Sharif University of Technology
Scientia Iranica
SCIENTIA
IRAN I CA
http://scientiairanica.sharif.edu

\title{
The deformation mechanism of a high rockfill dam during the construction and first impounding
}

\author{
A. Akhtarpour* and M. Salari \\ Department of Civil Engineering, Faculty of Engineering, Ferdowsi University of Mashhad, Mashhad, P.O. Box 917r5-1111, Iran.
}

Received 5 March 2017; received in revised form 6 January 2018; accepted 23 July 2018

\section{KEYWORDS}

High rockfill dam;

Hardening strain constitutive model;

Particle breakage;

Collapse settlement.

\begin{abstract}
The Masjed-e-Soleyman Dam is a tall rockfill dam with clay core, located in Iran. During the construction and first impounding, a considerably high excess pore water pressure was developed inside the core and, then, dissipated at a very slow rate; thus, the consolidation deformations were found insignificant. However, there were reports of noticeable internal deformations in the dam, and the crest also exhibited quick settlements during the first impounding. The main objective of this paper is to identify the deformation mechanism of this dam. For this purpose, the data recorded by its instruments were carefully studied and, then, a three-dimensional numerical model of the dam was developed. The mechanical behavior of materials was idealized by a hardening strain constitutive model. A numerical method was proposed based on this constitutive model and Rowe's stress-dilatancy theory to simulate the deformation behavior of coarse-grained materials, such as rockfills, due to particle size distribution, particle breakage, rotation, and rearrangement under shearing. The results show that the significant development of pore pressure in the core and its insignificant dissipation, plastic shear deformations inside the core, and extensive collapse settlements of the upstream shell are the main causes that influence the deformation mechanism.
\end{abstract}

(C) 2020 Sharif University of Technology. All rights reserved.

\section{Introduction}

Rockfill materials consist of sharp-edged aggregates obtained by blasting in rock borrow areas or rounded or sub-rounded aggregates excavated from river beds. These materials have had extensive use in the body of rockfill dams (e.g. [1-7]), the subgrade of roads, and a wide variety of other engineering structures. The high shear strength of these materials enables embankments to maintain steeper slopes. The strength and deformation behaviors of rockfill materials are conventionally

*. Corresponding author. Tel.: +98 5138805170

E-mail addresses: akhtarpour@um.ac.ir (A. Akhtarpour);

Salari.m@alumin.um.ac.ir (M. Salari)

doi: $10.24200 /$ sci. 2018.20778 investigated through large-scale triaxial tests (e.g. [815]). The mechanical behavior of granular materials can be simulated by a variety of constitutive models such as non-linear elastic model [16], elasto-plastic hardening model [17-19], and strain softening elastoplastic model [20]. It used to be a common practice to simulate the behavior of rockfill materials by linear or non-linear elastic models [21,22]; however, there are now a variety of advanced constitutive elasto-plastic models based on the disturbed state concept $[11,23,24]$ and critical state concept $[25,26]$ that can be used for modeling these materials. Previous laboratory pieces of research have revealed that Particle Size Distribution (PSD), particle breakage, rotation, and rearrangement have significant effects on the strength and deformation behaviors of coarse-grained materials (e.g. [10,14,27$31]$ ). Several creditable efforts have been made to incor- 
porate the impacts of these phenomena into mechanical constitutive models; these include the works carried out based on the disturbed state concept [24] and Rowe's stress-dilatancy theory $[25,26,32]$.

Laboratory investigations and field observations have detected the collapse behavior in a wide range of geotechnical materials (e.g. [33-38]). During the first impounding of central core rockfill dams, the collapse settlement inside the upstream shell can increase the settlement of rockfill shell relative to the core. For instance, during the first impounding of the Cherry Valley Dam, the settlement of the upstream shell was four times greater than that of the central core, which consequently led to the formation of longitudinal cracks on the crest along the shell-core interface $[39,40]$. Nobari and Duncan [41] proposed a technique for modeling this phenomenon. This technique relies on the hyperbolic model presented by Duncan and Chang [16] and is closely tied to the direct use of triaxial test results. Naylor et al. [42] proposed another method that combines the technique of Nobari and Duncan [41] with the critical state elastoplastic model. This method was used to simulate the collapse settlement of the rockfill shell of the Beliche Dam, located in Portugal [42-45]. Other researchers used porous media mechanics and unsaturated soil frameworks to develop other methods with similar objectives [46-48]. Recently, Mahinroosta and Alizadeh [49] used a concept called "stress reduction factor" to develop a practical technique for modeling the collapse settlement incorporated with a hardening/softening constitutive model [50] in the framework of saturated soil mechanics. This technique was used to simulate the collapse settlement of the rockfill shell of the Gotvand Dam, the tallest rockfill dam located in Iran [7].

The Masjed-e-Soleyman (MES) Dam is currently the second tallest rock-fill dam in Iran. This dam has exhibited a deformation behavior that is unique in comparison to other known high rockfill dams in the world. During its construction and first impounding, a considerably high excess pore water pressure was developed inside the core and dissipated at a very slow rate; therefore, the consolidation deformations were found negligible. However, there were reports of noticeable internal deformations in different parts of the dam-especially inside the core-during the construction. Moreover, the crest exhibited significant quick settlements during the first impounding. The main purpose of this research is to identify the deformation mechanism exhibited by this dam during the construction and first filling. To achieve this objective, first, the data recorded by the instruments installed inside the dam were studied to identify the main causes that influence its behavior. Moreover, a three-dimensional numerical model of the dam was developed to identify its deformation mechanism and determine the role of each effective cause influencing this mechanism. The calculations made simultaneous use of flow and mechanical formulations and also incorporated the water/soil interactions (consolidation phenomenon). The mechanical behavior of all materials of the embankment was simulated by an elasto-plastic hardening/softening constitutive model, built in finite difference Flac3D software [50]. This model was based on Mohr-Coulomb model. The difference, however, lies in the possibility that the cohesion, friction, dilation, and tensile strength may harden or soften after the onset of plastic yield. In this paper, the authors proposed a numerical method based on this constitutive model and Rowe's stressdilatancy theory to simulate the deformation behavior of coarse-grained materials, such as rockfills, due to PSD, particle breakage, rotation, and rearrangement under shearing. All parameters of the constitutive model for the coarse-grained zones were derived from the numerical simulation of the large-scale triaxial tests. The collapse settlement of the upstream rockfill shell during the first impounding was simulated by the technique proposed by Mahinroosta and Alizadeh [49].

\section{Masjed-e-Soleyman (MES) Dam}

The Masjed-e-Soleyman Dam previously named "Godar-e-Landar" is a 177-meter-high rockfill dam with the central core, located in the southwest of Iran on the Karun River. It has an installed capacity of $2000 \mathrm{MW}$, and its reservoir holds 261,000,000 cubic metres of water. The crest width and crest length of this dam are 15 and 500 meters, respectively. The main cross-section of this dam is shown in Figure 1. The rock mass surrounding the dam is part of Aghajari and Bakhtyari formations and consists of alternating layers of conglomerate and siltstone. This dam was constructed on a narrow valley of 18 meters wide at the river bed and with the average wall slope of $36^{\circ}$ to the horizon.

The geotechnical site investigations identified the Simband borrow area as the best potential source of material for the core (see region 1 in Figure 1). This borrow area consists of irregular alternating layers of clay (CL) and clayey gravel (GC); therefore, the core is a mixture of clay and gravel materials. The lower two-third part of the core was compacted with higher-than-standard optimum water content, and its upper one-third part was compacted with lower-thanstandard optimum water content. The shells consist of conglomerate aggregates obtained by blasting and were compacted without adding the required moisture. The aggregates of regions $3 \mathrm{~A}$ and $3 \mathrm{C}$ are coarser than those of $3 \mathrm{~B}$. The filter regions $(2 \mathrm{~A}, 2 \mathrm{~B}$, and $2 \mathrm{C}$ ) also consist of conglomerate aggregates with appropriate grading and were placed with traffic compaction [51].

To monitor the stress, pore pressure, and set- 


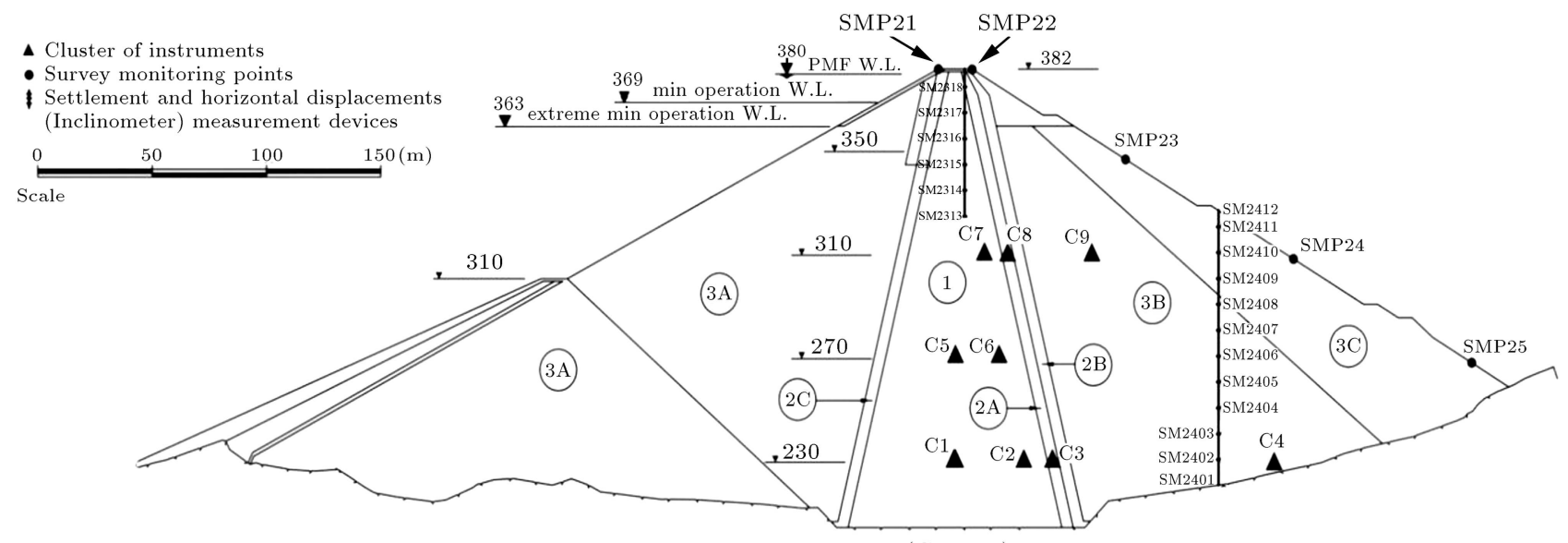

(CH. 260)

Figure 1. Different regions of dam and arrangement of undamaged instruments in its main cross-section (CH.260).

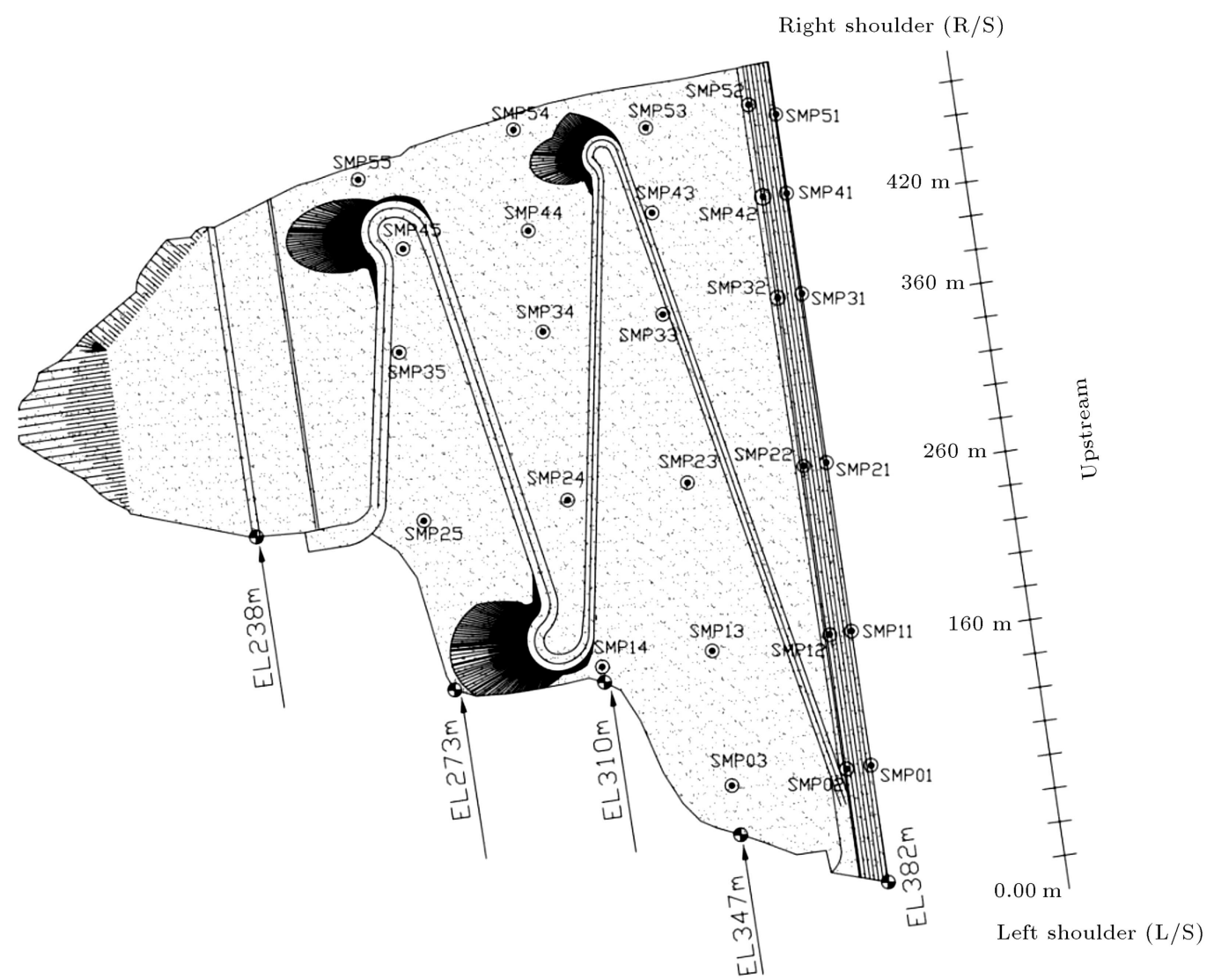

Figure 2. Arrangement of Survey Measurement Points (SMP) on the dam surface.

tlement inside the dam, a number of instruments were installed at cross chainages (CH.) 160, 260, 360, and 420 meters from the end of the crest (the left side); then, these instruments including the Electrical Piezometers (EP) and the Total Pressure Cells (TPC) installed in the core adjacent to the upstream shell and the Magnetic Plates (MPs) (for measuring internal settlements) installed at the lower levels of the core were damaged by the extreme deformations occurring during the construction of the final 50 meters of embankment. Figure 1 shows the arrangement of undamaged instruments in the main cross-section (CH.260) of the dam. In this figure, each cluster (C) includes three TPCs and one EP. These TPCs were installed at horizontal, 45 degrees upward and 45 degrees downward directions. About one month after the start of the first impounding, when the water reservoir level rose to about 57 meters, a system of Survey Measurement Points (SMP) was installed on the dam to measure surface displacements (see Figure 2). 


\section{Dam monitoring}

The fill load generated through the course of construction increases the total earth stress, leading to the development of excess pore water pressure and deformation in those parts. According to Nobari and Duncan [40], the water entering the upstream shell during the first impounding has four effects:

E1) Water pressure acting on the core;

E2) Water pressure acting on the foundation;

E3) Buoyancy in the upstream shell;

E4) Saturation collapse in the upstream shell (see Figure 3).

The evaluation of data recorded by the instruments reveals the following:

Pore water pressure: The pore pressure ratios of the core, $r_{u}$ (the excess pore pressure, $u$, divided by the overburden, $\gamma h$ ) at the instrumentation chainages for different levels are shown in Table 1. A number of causes such as lower parts of the core that have been compacted wet of optimum (high degree of saturation), the very low permeability of the core, and the relatively high rate of construction have led to the significant development of excess pore water pressure in the core during the construction. As shown in this table, at
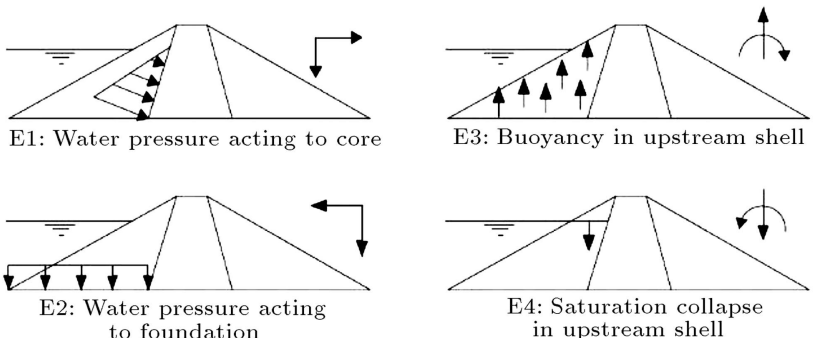

Figure 3. Effects of the first impounding on rockfill dams with central clay core. the lower levels of each chainage, an almost constant pore pressure ratio is prevailing between the center of the core and at the downstream locations of the core. This is indicative of very low excess pore pressure dissipation in the core. The very low permeability of the compacted core material is one of the causes behind this behavior. Moreover, as will be presented in the subsequent sections of this paper, as excess pore pressure dissipates and vertical effective stress increases, the permeability decreases exponentially. Reduced permeability of regions around the core and adjacent to the filters leads to the slower rate (speed) of dissipation. During the first impounding, the effects E1 and E4 have increased the pore pressure ratio in the core.

Total stress: The arching ratios of the core, $r_{A}$ (the vertical total stress, $\sigma_{y}$, divided by the overburden, $\gamma_{h}$ ), at the instrumentation chainages for different levels are shown in Table 2. During the first impounding, the effect $\mathrm{E} 1$ and the vertical component of the effect E4 have increased the arching ratio in the core. The reduction of these ratios at the downstream filter and shell during the first impounding can be attributed to rotational displacements of the TPCs installed in the horizontal direction due to the effects of the rotational component of the effect E4.

The real pore pressure ratios, $R_{u}$ (the excess pore pressure, $u$, divided by the vertical total stress, $\sigma_{y}$ ), are shown in Table 3 . In addition, the ratios of vertical total stress to horizontal total stress, $r_{K}$, are shown in Table 4. At lower parts of the core, $R_{u}$ and $r_{K}$ ratios are shown to be in unity or very close it (especially, in the middle chainages). These near-unity ratios can signify the presence of a near-zero effective stress zone with the isotropic stress condition at the lower levels of the core. Therefore, it appears that the core exhibits an almost incompressible behavior (quasi-fluid) in this zone: A behavior that has not been previously reported

Table 1. Pore pressure ratio, $r_{u}$, in the core.

\begin{tabular}{cccccccc}
\hline \multirow{2}{*}{ Chainage } & Installation level & \multicolumn{2}{c}{ End of construction } & & \multicolumn{2}{c}{ End of first filling } \\
\cline { 3 - 4 } & & Center line & Downstream & & Center line & Downstream \\
\hline+160 & +280 & 0.62 & 0.6 & & 0.65 & 0.63 \\
+160 & +310 & 0.35 & - & & 0.43 & - \\
+260 & +230 & 0.7 & 0.65 & & 0.7 & 0.67 \\
+260 & +270 & 0.6 & 0.58 & & 0.65 & 0.62 \\
+260 & +310 & 0.32 & - & - & 0.62 & - \\
+360 & +280 & 0.58 & 0.55 & & - & 0.45 & - \\
+360 & +310 & 0.41 & 0.33 & - & 0.32 & - \\
+430 & +310 & &
\end{tabular}


Table 2. Arching ratio, $r_{A}$, in the dam body.

\begin{tabular}{|c|c|c|c|c|c|c|c|c|c|}
\hline & & \multicolumn{4}{|c|}{ End of construction } & \multicolumn{4}{|c|}{ End of first filling } \\
\hline & & \multicolumn{2}{|c|}{ Core } & \multirow{2}{*}{$\begin{array}{c}\text { Filter } \\
2 \mathrm{~A}\end{array}$} & \multirow{2}{*}{$\begin{array}{c}\text { Shell } \\
\text { 3B }\end{array}$} & \multicolumn{2}{|c|}{ Core } & \multirow{2}{*}{$\begin{array}{c}\text { Filter } \\
\mathbf{2 A}\end{array}$} & \multirow{2}{*}{$\begin{array}{c}\text { Shell } \\
3 \mathrm{~B} \\
\end{array}$} \\
\hline & & Center line & Downstream & & & Center line & Downstream & & \\
\hline+160 & +280 & 0.66 & 0.66 & - & - & 0.68 & 0.68 & - & - \\
\hline+160 & +310 & - & 0.58 & 1.35 & 1.08 & - & 0.62 & 1.29 & 1.36 \\
\hline+260 & +230 & 0.68 & 0.77 & 1.38 & 0.49 & 0.7 & 0.78 & 0.99 & 0.47 \\
\hline+260 & +270 & 0.59 & 0.61 & - & - & 0.61 & 0.63 & - & - \\
\hline+260 & +310 & - & 0.43 & 1.45 & 0.81 & - & - & 1.37 & 0.68 \\
\hline+360 & +280 & 0.59 & 0.65 & - & 1.01 & 0.6 & 0.65 & - & 0.94 \\
\hline+360 & +310 & - & 0.58 & 1.59 & 0.68 & - & 0.66 & 1.49 & 0.53 \\
\hline+430 & +310 & - & 0.61 & 1.22 & 1 & - & 0.61 & 1.22 & 0.85 \\
\hline
\end{tabular}

Table 3. Real pore pressure ratio, $R_{u}$, in the core.

\begin{tabular}{|c|c|c|c|c|c|}
\hline \multirow{2}{*}{ Chainage } & \multirow{2}{*}{ Installation level } & \multicolumn{2}{|c|}{ End of construction } & \multicolumn{2}{|c|}{ End of first filling } \\
\hline & & Downstream & Center line & Downstream & Center line \\
\hline+160 & +280 & 0.91 & 0.94 & 0.93 & 0.95 \\
\hline+160 & +310 & - & 0.6 & - & 0.68 \\
\hline+260 & +230 & 0.95 & 0.9 & 0.96 & 0.89 \\
\hline+260 & +270 & 0.96 & 0.99 & 1 & 1 \\
\hline+260 & +310 & - & 0.7 & - & - \\
\hline+360 & +280 & 0.94 & 0.89 & 0.99 & 0.93 \\
\hline+360 & +310 & - & 0.68 & - & 0.74 \\
\hline+430 & +310 & - & 0.55 & - & 0.52 \\
\hline
\end{tabular}

Table 4. Ratio of vertical total stress to horizontal total stress, $r_{K}$, in the core.

\begin{tabular}{|c|c|c|c|c|c|}
\hline \multirow{2}{*}{ Chainage } & \multirow{2}{*}{ Installation level } & \multicolumn{2}{|c|}{ End of construction } & \multicolumn{2}{|c|}{ End of first filling } \\
\hline & & Downstream & Center line & Downstream & Center line \\
\hline+160 & +280 & 0.97 & 1 & - & 1.02 \\
\hline+160 & +310 & - & 0.7 & - & 0.85 \\
\hline+260 & +230 & 1.04 & 0.85 & 1 & 0.73 \\
\hline+260 & +270 & 0.91 & 0.97 & 1.02 & 0.98 \\
\hline+260 & +310 & - & 0.91 & - & - \\
\hline+360 & +280 & 0.99 & 0.88 & 1.01 & 0.95 \\
\hline+360 & +310 & - & 0.65 & - & 0.69 \\
\hline+430 & +310 & - & 0.64 & - & 0.62 \\
\hline
\end{tabular}

in the core of any zoned dam in the world. The significant development of excess pore water pressure in the lower parts of the core and very low rate of its dissipation are the main causes of forming this nearzero effective stress zone.

As mentioned, the three-component TPCs were installed in the dam. It is, therefore, possible to determine the magnitude and orientation of principal stresses $\sigma_{1}$ and $\sigma_{3}$. The determined $\sigma_{1}$ and $\sigma_{3}$ are acting in the plane perpendicular to the dam axis. Figure 4(a) depicts the relevant results for maincross section (CH.260) in terms of stress bars for the 


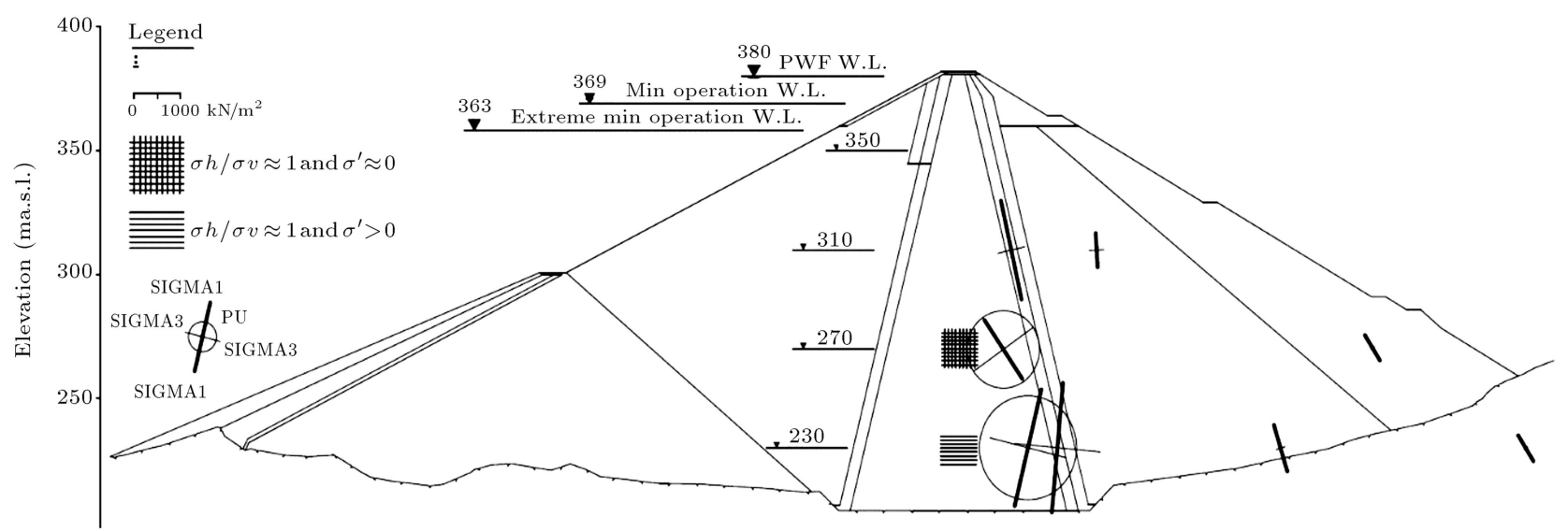

(a)

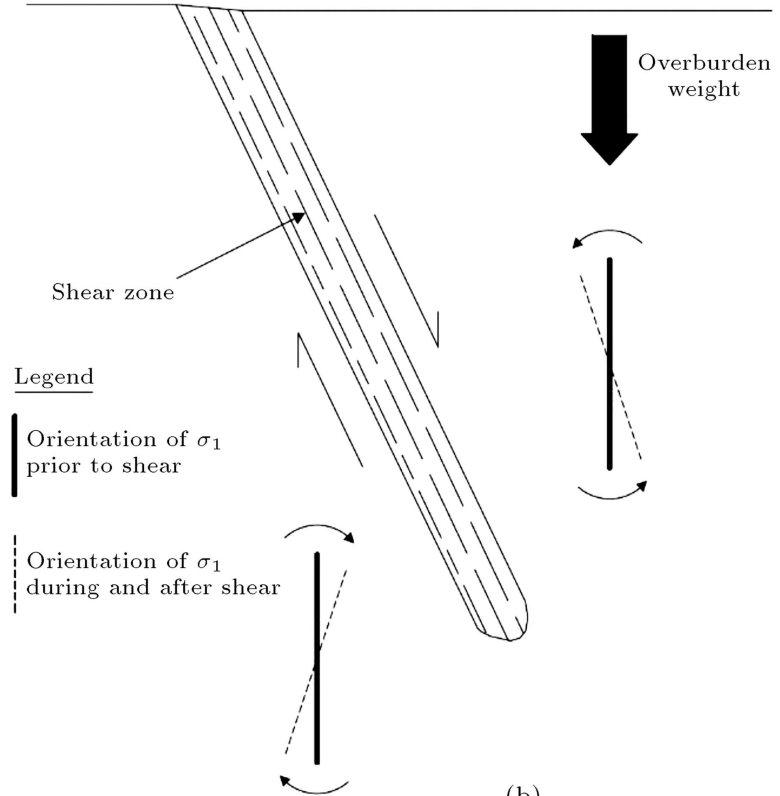

(b)

Figure 4. (a) The magnitude and orientation of principal stresses $\sigma_{1}$ and $\sigma_{3}$ acting in the plane perpendicular to the dam axis and relevant results in terms of stress bars for the measured total stress and circles for the measured pore pressures at the end of the first impounding. (b) The sketch of the inclined direction downward shear zone.

measured total stress and circles for the measured pore pressures at the end of the first impounding. At the center of the core, the measuring points were omitted, as these points consistently show almost isotropic earth pressure, meaning that the orientation of principal stresses becomes random. Instead, these zones are marked with a general signature. The areas in which the measurements yielded zero stresses are especially indicated (level: 270). The examination of Figure 4(a) shows that a substantial rotation in the principal stress direction has been monitored. At level 270 and above, an anti-clockwise rotation generally occurs in the core, whereas, at lower levels (level: 230), clockwise rotations have been monitored. This re-arrangement of principal stress directions is of systematic nature. It is indicative of a shear zone, which is progressing in the inclined direction downward as systematically sketched in Figure 4(b). In the core, such shear movement would be associated with a volume decrease (contractive behavior) and would more likely lead to a further rise rather than a relief of excess pore water pressures.

Deformation: Figure 5 shows the time variations of the data recorded by the MPs (installed along the central axis inside the core) and the SMP21 (positioned at the upstream of the crest) in the main cross-section. At the end of construction, the maximum recorded settlement in the core was 3.7 meters (about $2 \%$ of the dam height) and occurred at the level +314 (see MP-2312 in Figure 5). Apparently, this significant settlement recorded during the construction is not consistent with the significantly slow consolidation process in the core. The oblique shear zones in the core may play a major role in this inconsistency, as presented in the subsequent sections. 


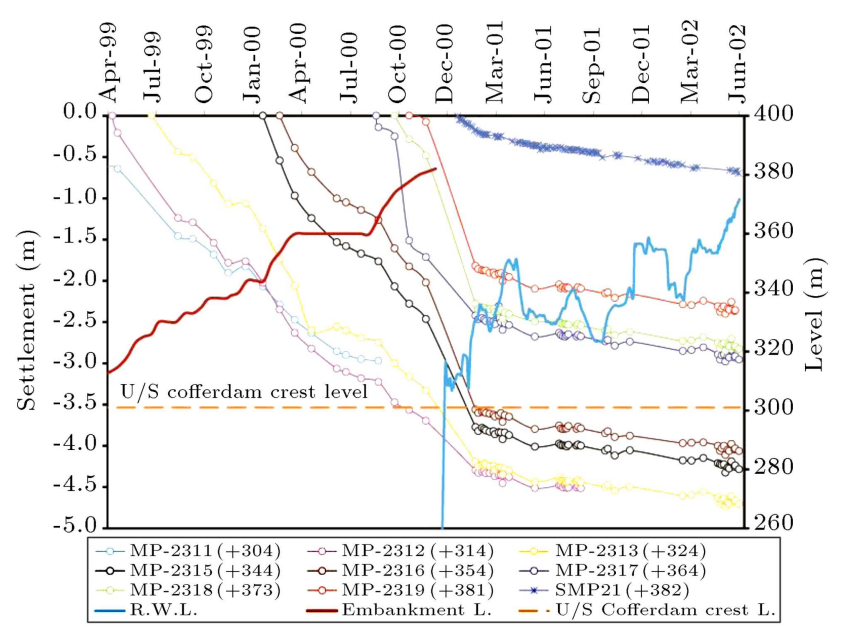

Figure 5. Settlement histories of the Magnetic Plates (MPs) installed along dam height in core centerline and SMP21 located at the upstream of the crest in the main cross-section (CH.260).

The effects of first impounding have caused a settlement of 2.2 meters (about $1.23 \%$ of the dam height) in the crest (see MP-2319 in Figure 5). Moreover, the increased excess pore pressure in the core in this period points toward negligible consolidation settlements. As mentioned, one month after the start of first impounding, when the water reservoir level had risen about 57 meters, a system of SMP was installed on the dam to measure surface displacements. The comparison of the settlement recorded by MP-2319 magnet plate and the settlement measured at survey point SMP21 (see Figure 5) indicates that almost half of the total settlement due to the first impounding has occurred during the first month after the start of impounding. The reason behind this observation is that, perhaps, before setting the system of SMPs, vast flood entered the reservoir, passing over the cofferdam (the crest level of the coffer dam is +301) and flooding a considerable volume of the upstream shell. The upstream rockfill shell that has been compacted without sufficient moisture is highly susceptible to collapse settlements. Therefore, the collapse settlements of the upstream rockfill shell are likely to be the main cause of the deformation behavior of the dam during the first impounding.

\section{Numerical modeling}

Given the relatively low crest length-to-dam height ratio $(=2.82)$, the behavior of the dam was simulated by a three-dimensional numerical model. The idealized three-dimensional geometry of the dam, its abutments, and their corresponding mesh are presented in Figure 6. Numerical modeling was performed by finite difference method in the FLAC3D program. The calculations utilized the flow and mechanical formulations simul-

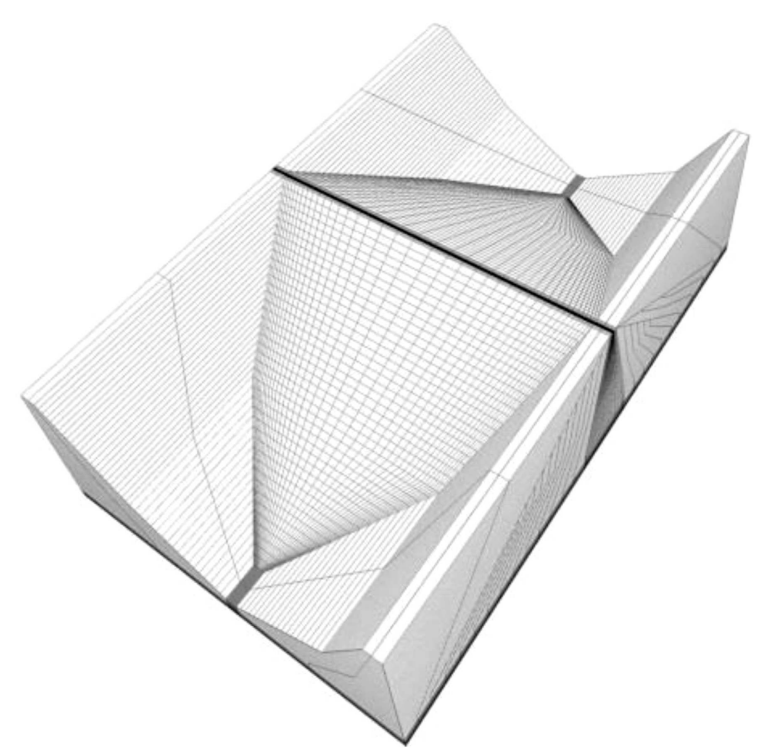

Figure 6. The three-dimensional idealized meshed model of the dam and its abutments.

taneously and, also, incorporated the water/soil interactions (consolidation phenomenon).

\subsection{Mechanical modeling}

The mechanical behavior of different materials of the dam was simulated by an elasto-plastic hardening/softening constitutive model built in the FLAC3D software [50]. This model has been developed based on Mohr-Coulomb constitutive model. In this model, the initial elastic behavior of the materials is simulated with Young's modulus $(E)$ and Poisson's ratio $(\nu)$; after the first yield, to simulate hardening/softening and dilative behaviors of material, the friction angle, cohesion, dilation angle, and tensile strength are mobilized as the functions of plastic shear strain and tensile strain, and their peak values are reached.

\subsubsection{Yield envelopes and potential functions}

Yield surface functions of this constitutive model are defined by Eqs. (1) and (2) as follows:

$$
\begin{aligned}
& f^{s}=\sigma_{1}-\sigma_{3} \frac{1-\sin \varphi_{m}}{1+\sin \varphi_{m}}+2 c_{m} \sqrt{\frac{1-\sin \varphi_{m}}{1+\sin \varphi_{m}}}, \\
& f^{t}=\sigma_{m}^{t}-\sigma_{3},
\end{aligned}
$$

where $f^{s}$ and $f^{t}$ are the shear and tensile yield functions, and $\sigma_{1}$ and $\sigma_{3}$ are the maximum and minimum principal stresses. In addition, $\varphi_{m}, c_{m}$, and $\sigma_{m}^{t}$ are the mobilized friction angle, mobilized cohesion, and mobilized tensile strength of the model, respectively.

This model used the non-associated flow rule for shearing and the associated flow rule for tension and defined the plastic potential functions as follows: 


$$
\begin{aligned}
& Q^{S}=\sigma_{1}-\sigma_{3} \frac{1-\sin \psi_{m}}{1+\sin \psi_{m}}, \\
& Q^{t}=-\sigma_{3},
\end{aligned}
$$

where $Q^{S}$ and $Q^{t}$ are the shear and tensile plas tic potential functions, and $\psi_{m}$ is the mobilized dilation angle.

\subsubsection{Stress-dependent elastic modulus}

In almost all geotechnical materials, the elastic modulus depends on the confining stress. Hence, Eq. (5) proposed in the hyperbolic (nonlinear elastic) model by Duncan and Chang [16] is applied in the constitutive model for the definition of this dependency. A number of researchers have confirmed the validity of this equation for a variety of soils and rocks under both laboratory and field conditions (e.g. $[7,22,52,53])$.

$$
E=K P_{a}\left(\frac{\sigma_{3}}{P_{a}}\right)^{n}
$$

where $E$ is the Young's modulus, $K$ is the elastic modulus, $P_{a}$ is the atmospheric pressure, and $n$ is the exponent of elastic modulus dependence on confining stress. Poisson's ratio $(\nu)$ is considered as a constant value, which is associated with the above-mentioned results of elasticity parameters in an appropriate response in the elastic domain of the constitutive model.

\subsubsection{Frictional hardening}

Vermeer and de Borst [54] proposed a relation for frictional hardening behavior of the geotechnical material. In this relation, the mobilized friction angle $\varphi_{m}$ depends on plastic shear strain and gradually increases to its peak value, $\varphi_{p}$. The authors modified this relation by introducing initial mobilized friction angle, $\varphi_{0}$. The resulting modified equation is shown below:

$$
\sin \varphi_{m}=\left\{\begin{aligned}
\sin \varphi_{0}+2 \frac{\sqrt{\varepsilon_{s}^{p} \times \varepsilon_{s}^{f}}}{\varepsilon_{s}^{p}+\varepsilon_{s}^{f}} & \left(\sin \varphi_{p}-\sin \varphi_{0}\right) \\
& \text { for } \varepsilon_{s}^{p} \leq \varepsilon_{s}^{f} \\
\sin \varphi_{p} & \text { for } \varepsilon_{s}^{p}>\varepsilon_{s}^{f}
\end{aligned}\right.
$$

where $\varepsilon_{s}^{p}$ is the plastic shear strain, and $\varepsilon_{s}^{f}$ is the plastic shear strain at peak friction angle. The parameter $\varphi_{0}$ controls the domain of elastic behavior to be exhibited by materials. This parameter can be defined as a function of confining stress.

\subsubsection{Dilatancy behavior}

Rowe [55] proposed Eq. (7) for dilatancy hardening behavior of geotechnical material:

$$
\sin \psi_{m}=\frac{\sin \varphi_{m}-\sin \varphi_{c v}}{1-\sin \varphi_{m} \sin \varphi_{c v}}
$$

where $\psi_{m}$ is the mobilized dilation angle, and $\varphi_{c v}$ is the critical state friction angle or friction angle of constant volume, which can be obtained from Eq. (8):

$$
\sin \varphi_{c v}=\frac{\sin \varphi_{p}-\sin \psi_{p}}{1-\sin \varphi_{p} \sin \psi_{p}},
$$

where $\psi_{p}$ is the peak dilation angle.

$\mathrm{Xu}$ and Song [25] reported that Eq. (7) must be modified prior to modeling the stress-dilatancy behaviors of rockfill materials. The main reasons for this requirement are summarized as follows:

1. The particle shape of rockfill material is irregular, and Rowe's stress-dilatancy equation is based on the irregular packing of uniform rods;

2. Particle breakage, rotation, and rearrangement are the primary causes of deformation of rockfill materials; however, particle slip is the primary mechanism in Rowe's stress-dilatancy theory;

3. The PSD in Rowe's stress-dilatancy theory is significantly different from that in rockfill materials;

4. The validation of Rowe's stress-dilatancy theory is primarily based on testing with sands and steel balls, which are more difficult to crush than rockfill materials.

Consequently, $\mathrm{Xu}$ and Song (2009) [25] proposed a simple revised form of Rowe's stress-dilatancy equation for rockfill material as follows:

$$
\sin \psi_{m}=R_{d} \frac{\sin \varphi_{m}-\sin \varphi_{c v}}{1-\sin \varphi_{m} \sin \varphi_{c v}},
$$

where $R_{d}$ is introduced as a reduction factor that is less than unity and reflects the effects of PSD, particle breakage, rotation, and rearrangement on the deformation of rockfill material.

Although Xu and Song [25] very well recognized the weaknesses of Rowe's mobilized dilation equation (Eq. (7)), as it will be presented in the following, the constitutive model modified by their equation lacks necessary comprehensiveness for the estimation of contractive volumetric strains of some rockfill materials, such as MES rockfill material, with high potential of particle breakage.

Under shearing such as the triaxial test, dense granular materials first contract in the elastic range and, then, undergo an irreversible dilation. However, when materials have a low density or have a potential for the particle breakage, rotation, and rearrangement, they experience irreversible contractive volumetric strains (contraction phase) before going into the dilation phase. The magnitude of these contractive volumetric strains depends on the intensity of the effects of the mentioned phenomenon on the deformation mechanism of materials. On occasions, the magnitude of contractive volumetric strains may 
be great enough to prevent or significantly mitigate the dilation. By definition, dilation $(d)$ is:

$$
d=\frac{d \varepsilon_{v}^{p}}{d \varepsilon_{s}^{p}}
$$

where $\varepsilon_{v}^{p}$ and $\varepsilon_{s}^{p}$ are the plastic volumetric strain and plastic shear strain, respectively. Ignoring dilatational elastic strain under triaxial condition gives Eq. (11):

$$
d=\frac{d \varepsilon_{v}^{p}}{d \varepsilon_{s}^{p}}=\frac{d \varepsilon_{v}^{p}}{d \varepsilon_{1}^{p}-\frac{1}{3} d \varepsilon_{v}^{p}}=\frac{\frac{d \varepsilon_{v}}{d \varepsilon_{1}}}{1-\frac{1}{3} \frac{d \varepsilon_{v}}{d \varepsilon_{1}}}
$$

where $\varepsilon_{v}, \varepsilon_{s}$, and $\varepsilon_{1}$ are the volumetric strain, shear strain, and axial strain, respectively. On the other hand, according to Rowe's theory, the relationship between dilation, $d$, and mobilized dilation angle, $\psi_{m}$, is in the form of Eq. (12):

$$
d=-\frac{6 \sin \psi_{m}}{3-\sin \psi_{m}}
$$

According to Eqs. (11) and (12), when $d \varepsilon_{v} / d \varepsilon_{1}>0$, $d>0$ and $-90^{\circ} \leq \psi_{m}<0$; this means that materials that are under shearing are contracting. However, when $d \varepsilon_{v} / d \varepsilon_{1}<0, d<0$ and $90^{\circ} \geq \psi_{m}>0$; this is means that materials are dilating. With this description, it is clear that greater initial contractive volumetric strains correspond to steeper initial slope of $\varepsilon_{v}-\varepsilon_{1}$ curve $\left(d \varepsilon_{v} / d \varepsilon_{1}<0\right)$ and lead to larger (more positive) values for dilation, $d$, and consequently lower (more negative) mobilized dilation angles, $\psi_{m}$.

According to $\mathrm{Xu}$ and Song [25], in Eq. (9), the reduction factor, $R_{d}$, is positive and less than unity. Therefore, under shearing, in the early stages of loading (contraction phase), the values obtained for mobilized dilation angle, $\psi_{m}$, from Rowe's equation (Eq. (7)) are smaller (more negative) than those obtained from Eq. (9). As a result, in this contraction phase, the contractive volumetric strains predicted by the hardening constitutive model modified by Eq. (9) will be lower than the ones predicted by the model modified by Eq. (7). Some rockfill materials such as those used in the shell of the MES Dam have a high potential for the particle breakage rotation and rearrangement phenomena. In other words, these materials exhibit significant contractive volumetric strains in the early stages of shear loading. Therefore, the constitutive model modified by Eq. (9) cannot adequately predict the contractive volumetric strains formed in these materials. In addition, in this research (which will be presented later), the results of the numerical simulation of large-scale triaxial tests on rockfill materials constituting the shell of the MES Dam show that, in the early stages of applying shear load, even the constitutive model modified by Rowe's equation (Eq. (7)) cannot adequately predict the contractive volumetric strains of these materials. In conclusion, as mentioned, it can be stated that although $\mathrm{Xu}$ and Song [25] very well recognized the weaknesses of Rowe's mobilized dilation equation (Eq. (7)), it appears that their equation lacks necessary comprehensiveness for the estimation of contractive volumetric strains, and the fourth reason for $\mathrm{Xu}$ and Song [25] in the case of the modification of Rowe's equation is not well reflected in their proposed equation (Eq. (9)). Xu and Song [25] validated their equation (Eq. (9)) based on the laboratory results of large-scale triaxial tests conducted by Varadarajan et al. [11]. These tests were conducted on sharp-edged limestone rockfill materials (obtained by blasting) and rounded to sub-rounded rockfill materials collected from the river bed. The results of these tests showed that the contractive volumetric strains of these materials at a confining stress of $1200 \mathrm{kPa}$ were at most $1.5 \%$; however, because of great particle breakage potential of conglomerate rockfill materials such as the ones constituting the shell of MES Dam, the magnitude of contractive volumetric strains of these materials in the same confining stress $(1200 \mathrm{kPa})$ is up to several times greater than that value (about 5\%). However, in the last stages of loading (dilation phase), the constitutive model modified by Eq. (9) can predict lower dilatational volumetric strains in comparison with the model modified by Eq. (7). Therefore, less-than-unity values of reduction factor $R_{d}$ can very well reflect the effects of PSD, particle breakage, rotation, and rearrangement on the deformation of rockfill material in the dilation stage. In view of these results, the authors propose Eq. (13) as a more comprehensive alternative to Eqs. (7) and (9):

$$
\sin \psi_{m}= \begin{cases}\sin \left(I_{c} \cdot \psi_{m R}\right) & -90^{\circ} \leq I_{C} \cdot \psi_{m R} \leq 0 \\ \sin \left(R_{d} \cdot \psi_{m R}\right) & 0<R_{d} \cdot \psi_{m R} \leq 90^{\circ}\end{cases}
$$

In the above equation, $\psi_{m R}$ is the mobilized dilation angle obtained from Rowe's equation (in degrees). $I_{c}$ is the contraction factor, which is greater than zero and can be greater than unity. This factor is a suitable measure for the quantitative assessment of the severity of the effects of PSD, particle breakage, rotation, and rearrangement on the deformation of rockfill materials during the contraction phase. The greater values of this factor lead to smaller (more negative) mobilized dilation angles and steeper initial slope, and the result is the greater value of contractive volumetric strains caused by the aforementioned deformation phenomenon. As mentioned, $R_{d}$ is the dilation reduction factor and is always positive and smaller than unity. This factor acts as a measure for quantitative assessment of the severity of the effects of PSD, particle breakage, rotation, and rearrangement on the deformation of rockfill materials during the dilation phase. The lower the value of this factor is, the 


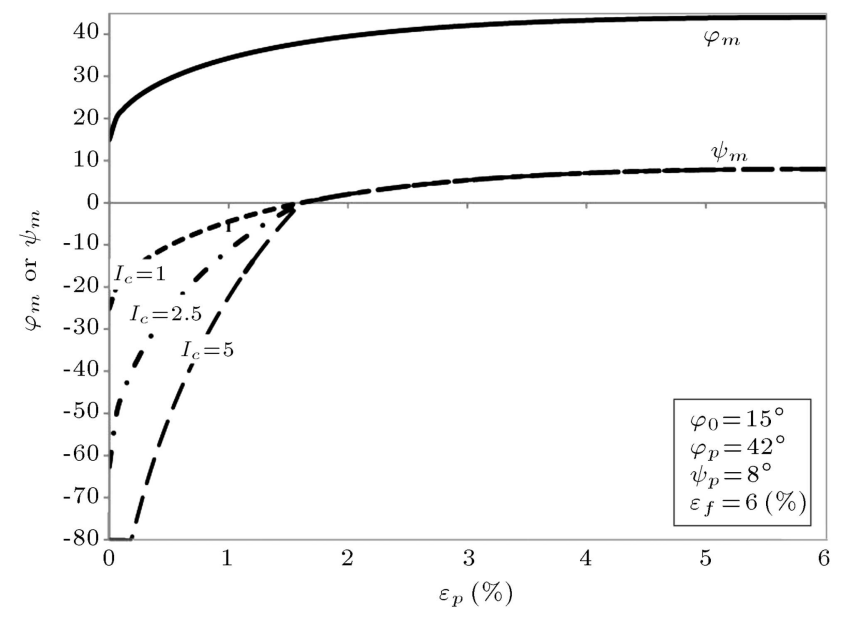

Figure 7. Variation of mobilized friction and dilation angles with a variation of $I_{c}$.

greater the effects of the aforementioned deformation phenomenon on the dilation of materials will be. In Eq. (13), these factors $\left(I_{c}\right.$ and $\left.R_{d}\right)$ are applied directly to Rowe's mobilized dilation angle, $\psi_{m R}$, (not to the sine of the angle); therefore, they can have a more precise effect on the changes of mobilized dilation angle. Figure 7 shows the curve expressing the changes of mobilized dilation angle for different $I_{c}$ values. As this figure shows, in the early stages of shear loading (contraction phase), as $I_{c}$ increases, the mobilized dilation angle, $\psi_{m}$, becomes smaller (more negative). Obviously, materials with greater contractive volumetric strains will have a greater $I_{c}$ value. These factors ( $I_{c}$ and $R_{d}$ ) will be obtained from the back analyses on the triaxial test results. It should be mentioned that to incorporate the confining pressure into the mentioned deformation phenomenon (especially, the particle breakage phenomenon), factors $I_{c}$ and $R_{d}$ can be considered as the functions of confining stress.

\subsubsection{Stress dependent peak friction and dilation angle}

Laboratory tests indicated that the maximum friction angles depended on the confining pressure. As a result, this dependency is accounted for in the constitutive model by the application of Eq. (14). This stressdependent friction angle is used as the maximum friction in Eq. (8):

$$
\varphi_{p}=\varphi_{s}-\Delta \varphi \log \left(\frac{\sigma_{3}}{P_{a}}\right),
$$

where $\varphi_{p}$ is the maximum friction angle, $\sigma_{3}$ is the minor principal stress, and $\varphi_{s}$ is the angle of internal friction at $\sigma_{3}=100 \mathrm{kPa}, P_{a}$ is the atmospheric pressure, $\Delta \varphi$ is the reduction in the friction angle with respect to the confining pressure for each 10-fold increase in $\sigma_{3}$.

In addition, for geotechnical materials, the maximum dilation angle, $\psi_{p}$, depends on confining pressure.
Generally, the peak dilation angle, $\psi_{p}$, decreases with the increase of confining pressure, $\sigma_{3}$.

\subsubsection{Large-scale triaxial tests simulation}

A series of conventional triaxial tests were conducted on the samples taken from the materials constituting the core; these tests were performed on samples with CL: GC ratios of 40:60, 60:40, and 80:20. Moreover, a series of large-scale triaxial tests have been conducted at Karlsruhe University [56] on the coarse-grained materials of the shell, filter, and drainage regions of this dam. As mentioned earlier, these materials consist of crushed particles obtained by blasting in calcareous conglomerate borrow area of the MES Dam. There are several methods for scaling down the size of the materials, e.g., scalping (cut-off), replacement of materials, generation of quadratic size distribution curve, and parallel gradation techniques [11,57]. The last method was found to be more appropriate for this material. The large-scale triaxial tests were performed on specimens with a height of 80 centimeters and a diameter of 80 centimeters. Other pieces of research have shown that the values of marshal particle breakage Index [8] for these kinds of rockfill materials are significantly high $[52,53]$. Therefore, this material has a high potential for crushing under shearing.

To extract some parameters of this modified constitutive model for the materials of the dam body, the conventional and large-scale triaxial tests on the body materials were simulated in FLAC software environment. All functions and equations described in the previous sections were coded into the constitutive model by FISH language embedded in the software. Simulations were conducted on a single element with axial symmetry and appropriate boundary condition (see Figure 8). In each step of the analysis, the coded program computed the plastic shear strain and updated the model parameters based on the defined functions and equations. For instance, Figures 9 and 10 show the simulations conducted for rockfill materials

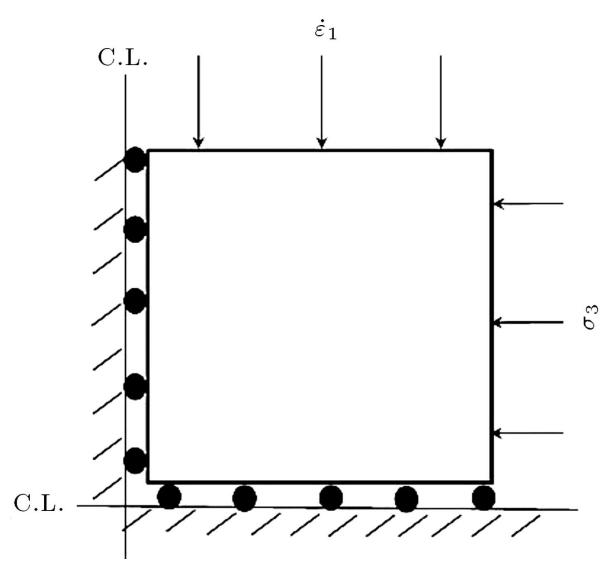

Figure 8. The numerical model of triaxial test in FLAC 2D. 


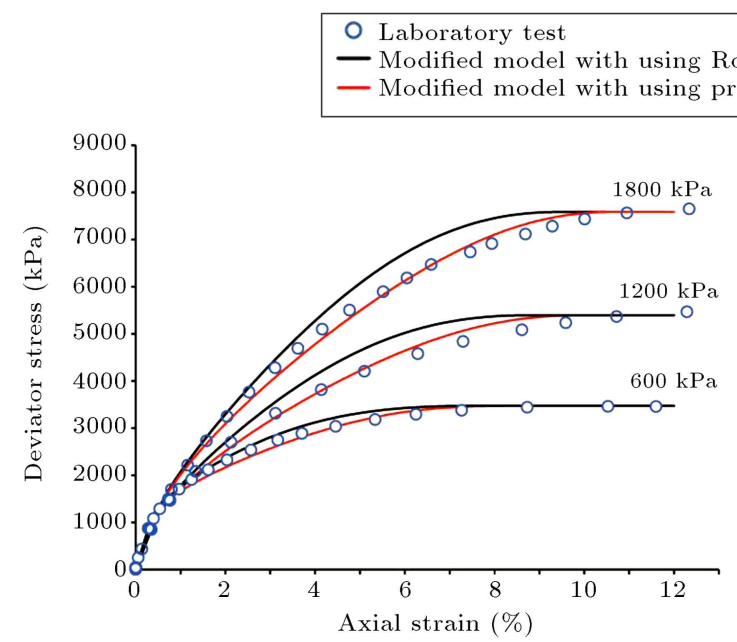

(a)

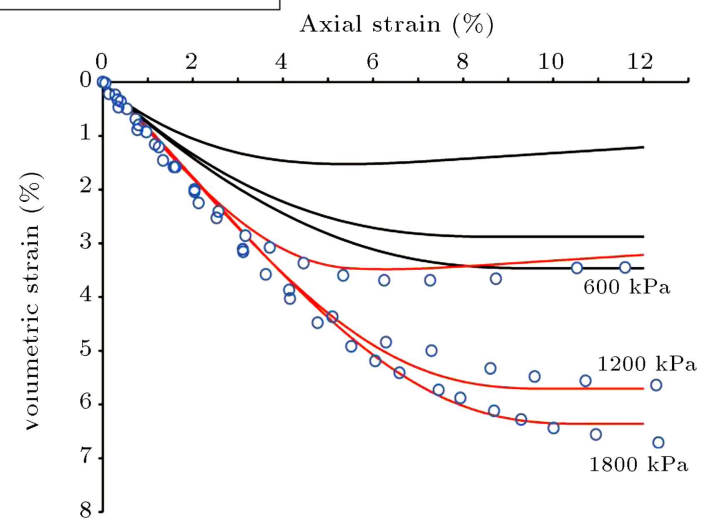

(b)

Figure 9. Comparison of modeled and observed large triaxial test results for rockfills used in regions $3 \mathrm{~A}$ and $3 \mathrm{C}$ under the initially dry condition.

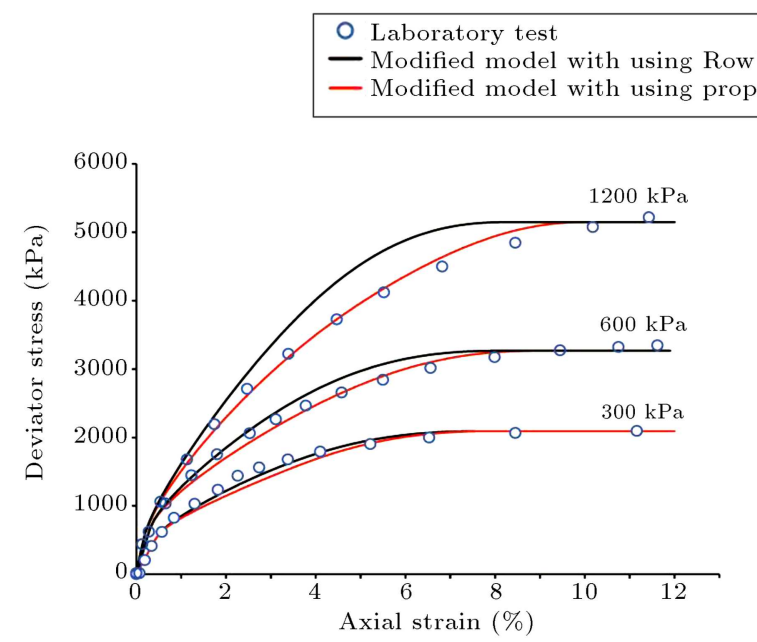

(a)
Axial strain (\%)

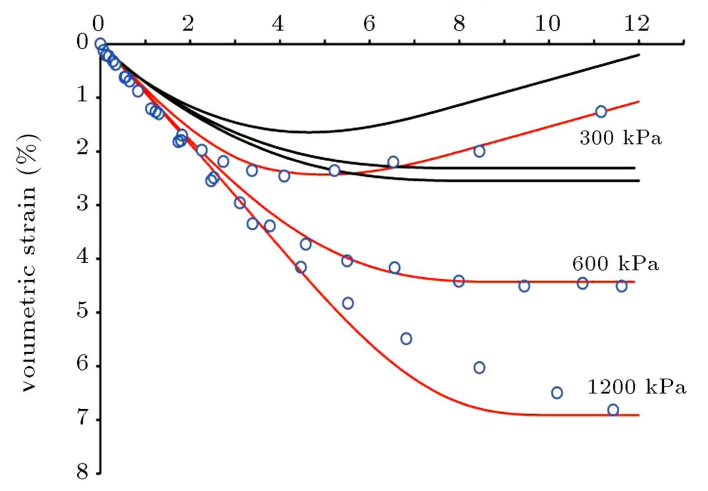

(b)

Figure 10. Comparison of modeled and observed large triaxial test results for rockfills used in regions $3 \mathrm{~A}$ and $3 \mathrm{C}$ under the initially saturated condition.

used in regions $3 \mathrm{~A}$ and $3 \mathrm{C}$ under the initially dry and saturated conditions. These figures demonstrate a better simulated volume change behavior attained by the mobilized dilation angle equation proposed in this paper (Eq. (13)) rather than Rowe's equation (Eq. (7)). The final parameters of this modified constitutive model for different regions of the dam are shown in Table 5. In this analysis, the cohesion $\mathrm{C}$ of materials was not considered to be mobilized and was set equal to the intercept of the tangent to the Mohr's circles resulting from triaxial tests. As shown in this table, $n$ and $K$ parameters in Eq. (5) are determined by Duncan and Chang' proposed method [16] using the laboratory results of triaxial tests. Poisson's ratio $(\nu)$ is considered as a constant value and determined from the initial slope of $\varepsilon_{v}-\varepsilon_{1}$ curve of the laboratory results. Initial mobilized friction, $\varphi_{0}$, in Eq. (6) is determined from the initial part of $q-\varepsilon_{1}$ curve, where $q$ is the deviator stress. This parameter can be defined as a function of confining stress. The response of material in the elastic domain of the constitutive model is controlled by these five parameters. The peak fiction angle, $\varphi_{P}$, and peak dilation angle, $\psi_{P}$, in Eqs. (6) and (7) are defined as logarithmic functions of confining stress. These functions are determined from plotting these parameters versus the logarithm of confining stress. As mentioned in the previous section, contraction factor, $I_{c}$, and reduction factor, $R_{d}$, in Eq. (13) control the shape of $\varepsilon_{v}-\varepsilon_{1}$ curve in the contraction and dilation phases under shearing, respectively. As shown in Figure 7, these two parameters were extracted for each confining stress through trial analyses, and they can be defined as a function of confining stress.

As shown in Table 5, the exponent $(n)$ of elastic 
Table 5. The mechanical and flow parameters of the different regions of the embankment.

\begin{tabular}{|c|c|c|c|c|c|c|}
\hline Zone & $\begin{array}{c}3 \mathrm{~A}, 3 \mathrm{C} \\
\text { (saturated) }\end{array}$ & $\begin{array}{c}3 \mathrm{~A}, 3 \mathrm{C} \\
(\mathrm{dry})\end{array}$ & $3 B$ & $2 \mathrm{~A}$ & $2 \mathrm{~B}, 2 \mathrm{C}$ & Core \\
\hline$\rho_{d}\left(\frac{\mathrm{gr}}{\mathrm{cm}^{3}}\right)$ & 2 & 2 & 2 & 1.9 & 2.1 & 1.89 \\
\hline$n$ & 0.74 & -0.12 & 0.05 & 1 & 0 & 0.8 \\
\hline$K$ & 556 & 3672 & 422 & 138 & 1663 & 120 \\
\hline$V$ & 0.1 & 0.1 & 0.2 & 0.15 & 0.1 & 0.15 \\
\hline$C\left(\frac{\mathrm{kN}}{\mathrm{m}^{2}}\right)$ & 25 & 65 & 40 & 10 & 20 & 30 \\
\hline$\varepsilon_{f}(\%)$ & 6 & 6 & 7 & 8.5 & 8.5 & 10 \\
\hline$I_{d}$ & $0.77 \cdot\left(\frac{\sigma_{3}}{P_{a}}\right)+0.25$ & 5 & 2.5 & 3.5 & 1 & 1 \\
\hline$R_{d}$ & 1 & 1 & 1 & 1 & 1 & 1 \\
\hline$\varphi_{P}$ & $55-11 \log \left(\frac{\sigma_{3}}{P_{a}}\right)$ & $51.3-7 \log \left(\frac{\sigma_{3}}{P_{a}}\right)$ & $42.2-0.64 \log \left(\frac{\sigma_{3}}{P_{a}}\right)$ & $45-6.64 \log \left(\frac{\sigma_{3}}{P_{a}}\right)$ & $46.4-4.8 \log \left(\frac{\sigma_{3}}{P_{a}}\right)$ & 30 \\
\hline$\psi_{P}$ & $\begin{cases}5.5 & \frac{\sigma_{3}}{P_{a}} \leq 3 \\
0.0 & \frac{\sigma_{3}}{P_{a}}>3\end{cases}$ & $\begin{cases}1.5 & \frac{\sigma_{3}}{P_{a}} \leq 6 \\
0.0 & \frac{\sigma_{3}}{P_{a}}>6\end{cases}$ & 0 & 0 & $1.15-0.83 \log \left(\frac{\sigma_{3}}{P_{a}}\right)$ & 0 \\
\hline$\varphi_{0}$ & $42-30 \log \left(\frac{\sigma_{3}}{P_{a}}\right)$ & $33.6-16.6 \log \left(\frac{\sigma_{3}}{P_{a}}\right)$ & $4.2-20 \log \left(\frac{\sigma_{3}}{P_{a}}\right)$ & $40-2.7 \log \left(\frac{\sigma_{3}}{P_{a}}\right)$ & $30-2.6 \log \left(\frac{\sigma_{3}}{P_{a}}\right)$ & 0 \\
\hline$K_{\text {int }}(\mathrm{cm} / \mathrm{s})$ & $1 \times 10^{-1}$ & $1 \times 10^{-1}$ & $1 \times 10^{-4}$ & $2 \times 10^{-2}$ & $1 \times 10^{-2}$ & Eq. (17) \\
\hline
\end{tabular}

Table 6. The mechanical and flow parameters of the rock mass.

\begin{tabular}{ccccc}
\hline Model & $\begin{array}{c}\boldsymbol{\rho}_{\boldsymbol{d}} \\
\left(\frac{\mathrm{gr}}{\mathbf{c m}^{3}}\right)\end{array}$ & $\begin{array}{c}\boldsymbol{E} \\
(\mathbf{G P a})\end{array}$ & $\boldsymbol{v}$ & $\begin{array}{c}\boldsymbol{K}_{\text {int }} \\
(\mathbf{c m} / \mathbf{s})\end{array}$ \\
\hline Linear elastic & 2.4 & 2 & 0.25 & $5 \times 10^{-8}$ \\
\hline
\end{tabular}

modulus dependence on confining stress for regions $3 \mathrm{~A}$ and $3 \mathrm{C}$ under the initially dry conditions is negative. This means that as confining stress increases, the elastic component of Young's modulus of these materials decreases (see Eq. (5)). This phenomenon can be attributed to more intense particle breakage of the material. The maximum values of $I_{c}$ were also obtained for regions $3 \mathrm{~A}$ and $3 \mathrm{C}$, which again point to more intense breakage than other regions. Considering the fine-grained nature of core materials making the breakage next to impossible, $I_{c}$ of these materials was considered to be unity.

The comparison of the volumetric strains of the initially dry and saturated specimens at the same confining stress (see Figures 9(a) and 10(a)) shows that initial saturation can significantly increase the volumetric strain, as it can facilitate the sliding of particles over each other. This indicates that, during the construction, the rockfill materials of the shell should have been extensively wetted with high-pressure water jets to prevent significant settlements of the upstream shell during the first impounding. Given the noticeable stiffness of the surrounding rock mass, it was simulated with the linear elastic constitutive model. Table 6 shows the parameters of this material.

\subsection{Flow modeling}

The application of coupled mechanical-flow analysis necessitates the introduction of fluid flow formulation. The formulation implemented in the FLAC3D software [50] is presented in Appendix A. In this formulation, the permeability tensor, $K$, is split into an intrinsic part, $K_{i n t}$, and a relative part, $k_{r}$, as follows:

$$
K=K_{\text {int }}(n) k_{r}\left(S_{w}\right) .
$$

The intrinsic permeability, $K_{\text {int }}$, reflects the influence of the porous matrix on the water transfers. That is to say, intrinsic permeability is the saturated soil water permeability and depends on the total porosity, $n$. The relative permeability reflects only the fluid properties. Therefore, it is assumed to be a function of the saturation degree, $S_{w}$, which may be computed by Eq. (16):

$$
k_{r}\left(S_{w}\right)=\left(2-3 S_{w}\right) S_{w}^{2} .
$$

Based on some simplifying assumptions made in FLAC3D, Figure 11 is employed as the predefined retention curve of the model to explain the relationship between saturation degree and interstitial fluid

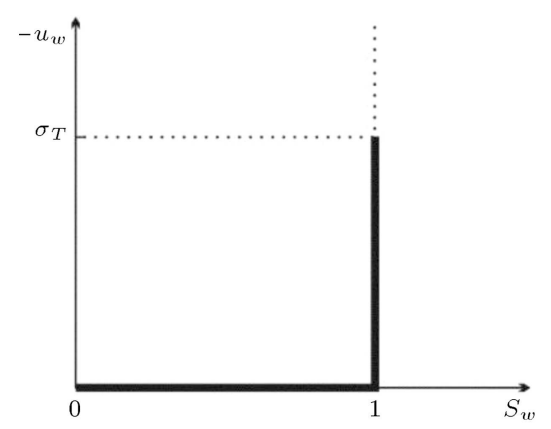

Figure 11. Assumed retention curve in FLAC3D [50]. 
pressure. In this figure, $\sigma_{T}$ is the fluid tension limit (negative number) and, physically, is a tension that would be sustained by pore water. As the fluid pressure tries to drop below the set limit, cavitation occurs, and the interstitial pressure is then set to zero. Depending on conditions, the degree of saturation may also fall below one. If the saturation degree remains equal to one, the further expansion of the pore volume could cause negative pore pressures to increase again [50].

The value of intrinsic permeability, $K_{\text {int }}$, or the saturated soil permeability in each part of the numerical model was determined based on the results of permeability and consolidation tests. For simplicity's sake, $K_{\text {int }}$ of all regions of the numerical model, except the core, was assumed to be a constant value (based on the initially estimated porosity). A series of consolidation tests were conducted on the core materials, and the results of these tests showed that the vertical permeability of the core increased with the increase of vertical effective stress. Statistical operations performed on the test results yielded a basic power function for vertical permeability of the core materials. The only variable of this function is the vertical effective stress, $\sigma_{y}^{\prime}$. Ultimately, the exact values of the coefficients of this basic function and the horizontal-to-vertical permeability ratio of the core materials were determined through trial analyses:

$$
\begin{aligned}
& K_{\text {int }}(y)= \begin{cases}2 \times 10^{-8} & \sigma_{y}^{\prime} \leq 150 \\
1.82 \times 10^{-6}\left(\frac{\sigma_{y}^{\prime}}{P_{a}}\right)^{-0.48} & \sigma_{y}^{\prime} \geq 150\end{cases} \\
& \frac{K_{\text {int }(x)}}{K_{\text {int }(y)}}=2.5
\end{aligned}
$$

where $K_{\text {int }(x)}$ and $K_{\text {int }(y)}$ are the horizontal and vertical saturated permeability coefficients (in $\mathrm{cm} / \mathrm{s}$ ), and $\sigma_{y}^{\prime}$ is the vertical effective stress (in $\mathrm{kPa}$ ). This function was also coded by the FISH programming language. Tables 5 and 6 present the intrinsic permeability of the porous media for other regions.

\subsection{Sequences of modeling}

The dam construction was finished after about five years in November 2000. In this analysis, forty-two layers were used in the simulation of construction. A month after the end of construction, the first filling started. At the beginning of the first filling, the reservoir water level was +255 . Due to heavy rains and floods, the reservoir water level increased by an average of $2 \mathrm{~m} /$ day (with a peak increase of $6 \mathrm{~m} /$ day) to about 57 meters in 28 days; then, it climbed another 18 meters in the next 30 days (by an average of $0.6 \mathrm{~m} /$ day) and, after about another 16 months, the reservoir water level reached its normal level $(+371)$. In this model, the four impounding effects were idealized in six stages (see Figure 3). The first three impounding

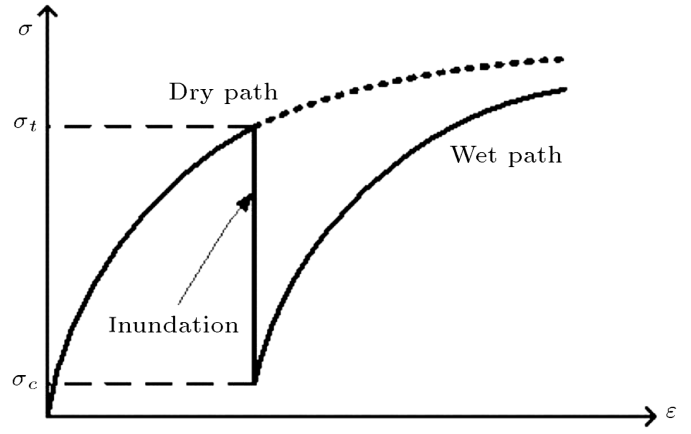

Figure 12. Comparison of stress strain curves between dry sample and that followed by saturation [7].

effects (E1 to E3) were simulated by applying the pore pressure proportionate to water level (in each stage of impounding) on the nodes of upstream shell, foundations, and filter elements and applying water pressure to the outer surface of the upstream shell and foundation. The collapse settlement was simulated using the practical technique proposed by Mahinroosta and Alizadeh [49]. This technique has two steps:

i) Reducing all components of effective compressive stress of the recently saturated layer by multiplying them by stress reduction coefficient $\left(C_{c}\right)$;

ii) Allocating the saturation parameters to the recently saturated layer.

The stress reduction coefficient $\left(C_{c}\right)$ is less than unity. The lower the value of this coefficient is, the greater the collapse settlement will be. This coefficient should be determined by special triaxial tests on the materials. Figure 12 shows an idealized triaxial test of this type. According to Figure 12 containing a hypothetical stress path, when a dry rockfill medium is submerged, internal stresses decrease vertically from its initial value $\sigma_{t}$ to the collapse stress $\sigma_{c}$; therefore, this coefficient, $C_{c}$, equals the ratio $\sigma_{c} / \sigma_{t}$. Dependency of the collapse phenomenon on confining pressure has been observed by a number of researchers $[49,7,58-$ $60]$. Thus, this coefficient was defined as a function of confining stress [49]. Unfortunately, this kind of special triaxial tests was not conducted in this project. Therefore, this coefficient was determined from trial analyses in each stage of impounding (see Table 7). As can be seen in Table 7 , this coefficient is smaller in the early stages of impounding. This is because the lower parts of the upstream shell are under greater confining stresses, naturally intensifying the particle breakage and, ultimately, causing the collapse deformations of these early stages to be greater than those of later stages.

\subsection{Calibration of the $3 D$ numerical model}

The formulation of the analytical model was carried out within the continuum media mechanic framework. 
Table 7. The range of reservoir water level, duration, and stress reduction coefficient for each stage of impounding.

\begin{tabular}{lcccccc}
\hline \multicolumn{1}{c}{ Stage of impounding } & $\mathbf{1}$ & $\mathbf{2}$ & $\mathbf{3}$ & $\mathbf{4}$ & $\mathbf{5}$ & $\mathbf{6}$ \\
\hline Range of reservoir water level (m) & $255-288$ & $288-312$ & $312-328$ & $328-335$ & $335-357$ & $357-371$ \\
Duration (day) & 1 & 9 & 49 & 12 & 446 & 34 \\
$C_{C}$ & 0.1 & 0.1 & 0.8 & 0.8 & 0.8 & 0.8 \\
\hline
\end{tabular}

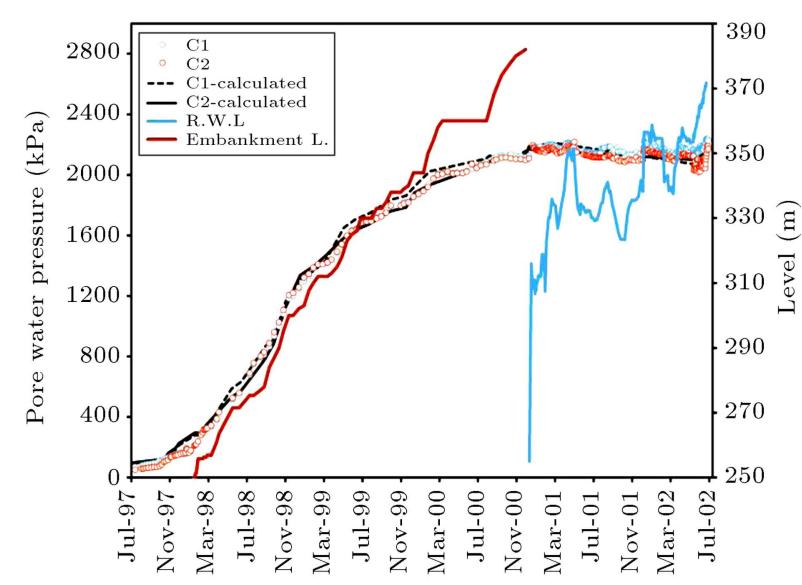

(a)

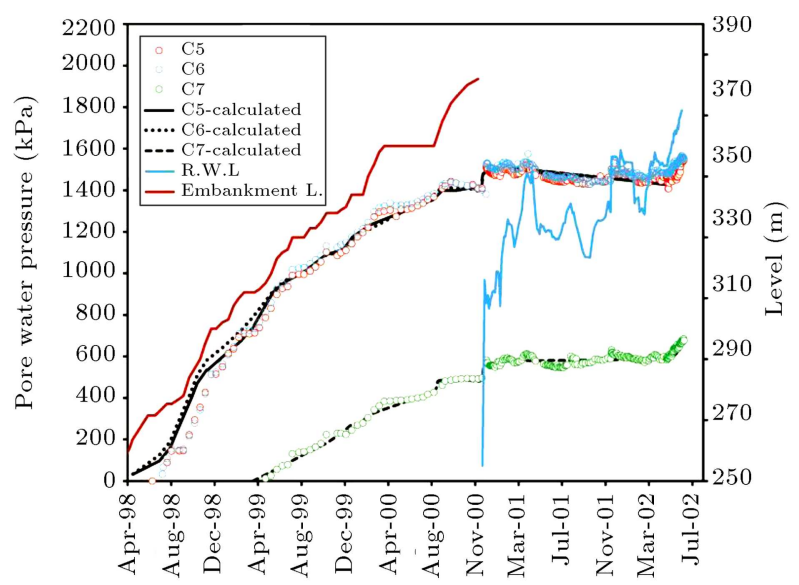

(b)

Figure 13. Comparison of measured and calculated excess pore water pressures within the core in the main cross-section (CH.260).

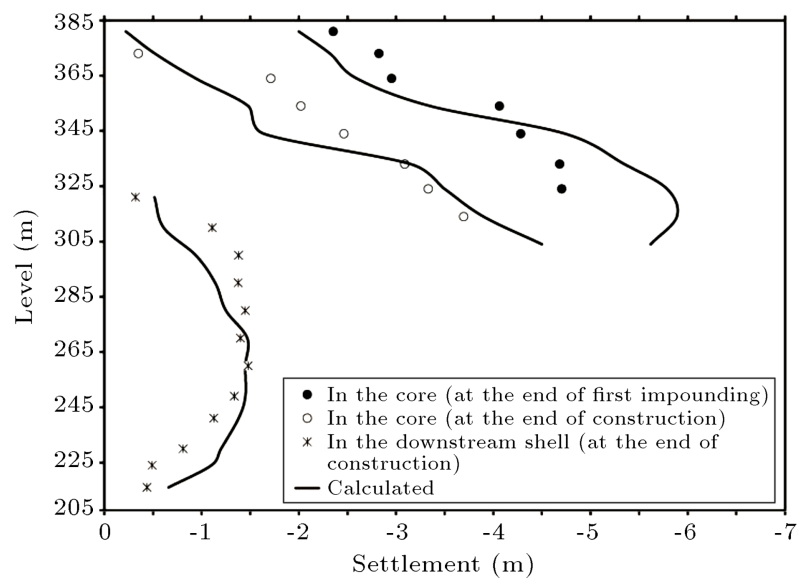

Figure 14. Comparison of measured and calculated settlements of the Magnetic Plates (MPs) installed along dam height in core centerline and downstream shell in the main cross-section (CH.260).

Therefore, according to a study by Pagano et al. [61], the back analyses must be based upon quantities having a higher degree of representativeness. They showed that the displacements and pore water pressure (assuming a hydraulic equilibrium in porous media) have a higher degree of representativeness than other quantities (e.g., stress, strain, etc.); thus, in this paper, the calibration of analytical model was performed accordingly. Figure 13 shows the variation of measured and calculated values of pore pressure at the main cross chainage $(+260 \mathrm{~m})$ during the construction and first impounding. Figures 14 and 15 show the variations

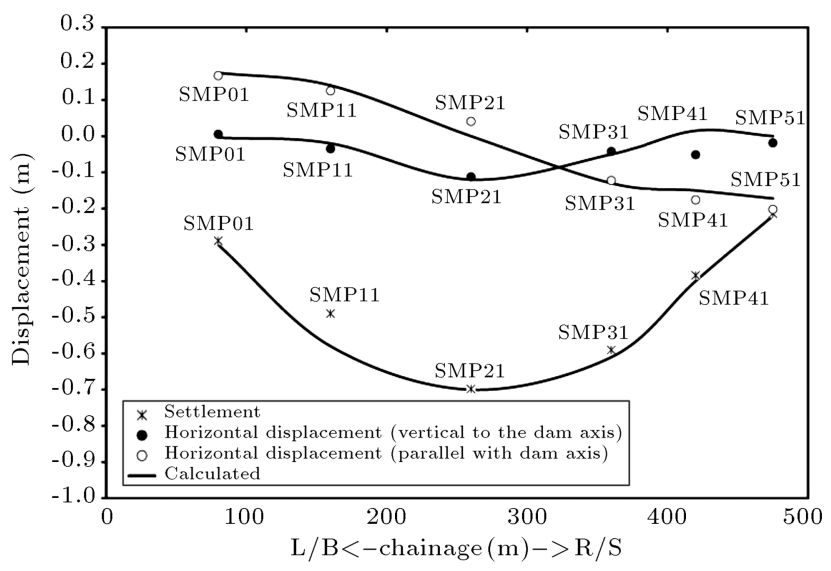

Figure 15. Comparison of measured and calculated surface displacements of the Survey Measurement Points (SMPs) located at the upstream of the crest.

of the measured and calculated values of deformation through the course of analysis. These figures show good agreement between measured and computed values, which in turn points to the highly accurate calibration of the three-dimensional analytic model.

\section{Numerical results and discussion}

Figures 16 and 17 show the contour distribution of pore pressure in the main cross-section ( $\mathrm{CH} .260)$ at the end of construction and first impounding, respectively. As mentioned, the upper part of the core has been placed on the dry side of standard optimum moisture content; 


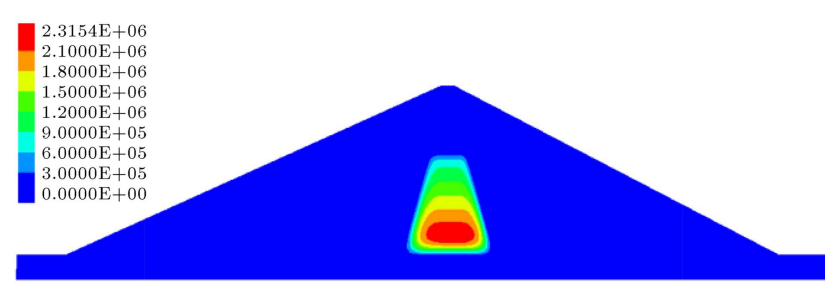

Figure 16. Contours of pore water pressure (in $\mathrm{Pa}$ ) at the end of construction.

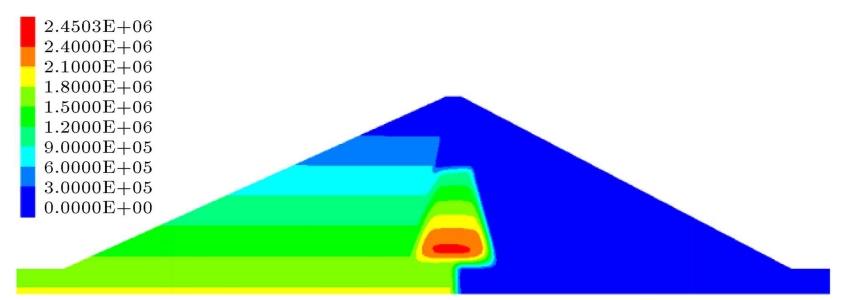

Figure 17. Contours of pore water pressure $(\mathrm{Pa})$ at the end of the first impounding.

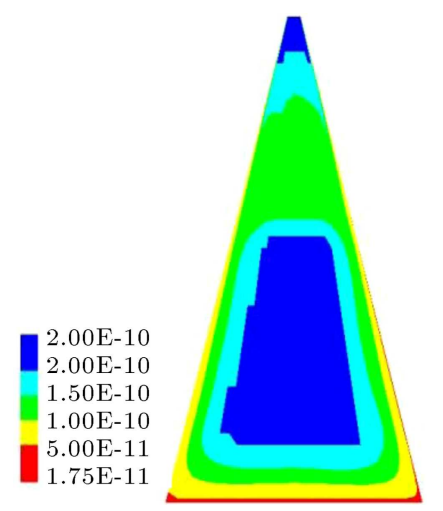

Figure 18. Contours of vertical permeability $(\mathrm{m} / \mathrm{s})$ within the core at the end of the first impounding.

thus, during the construction, the excess pore pressure could not be developed in this part. However, a very high excess pore pressure was developed at the lower parts of the core. As mentioned in Section 3, a number of causes such as lower parts of the core that have been compacted wet of optimum (high degree of saturation), the very low permeability of the core, and the relatively high rate of construction have led to the significant development of the excess pore water pressure in the core during the construction.

According to Eq. (17), as excess pore pressure dissipates and vertical effective stress increases, the permeability decreases exponentially. Figure 18 shows the contour distribution of vertical permeability in the main cross-section (CH.260) at the end of construction. Reduced permeability of regions around the core and adjacent to the filters leads to a slower rate (speed) of dissipation and consolidation. In the core, from the trial analyses, the ratio of horizontal to vertical permeability coefficients is 2.5 (see Eq. (17)). Therefore, the contours of excess pore pressure have an ellipse

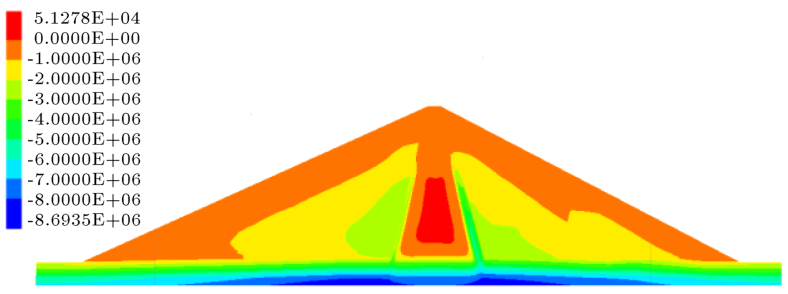

Figure 19. Contours of effective vertical stress $(\mathrm{Pa})$ at the end of construction.

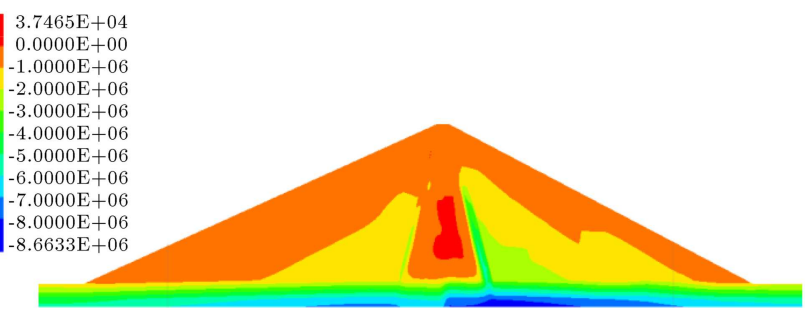

Figure 20. Contours of effective vertical stress $(\mathrm{Pa})$ at the end of the first impounding.

shape. At the lower levels of the core, the almost constant excess pore pressure is prevailing between the center of the core and at the downstream or upstream locations of it. These results were confirmed by the data obtained from EPs installed at those locations (see Section 3).

During the first impounding, due to the abovementioned causes, the core is almost under the undrained condition. The water pressure acting on the core and saturation collapse in upstream shell (see Figure 3) can be important factors in the increase of excess pore water pressure in the core

Figures 19 and 20 show the contour distribution of vertical effective stress in the main cross-section at the end of construction and first impounding. The middle regions of the core at the lower parts have (approximately) zero-effective stress and exhibit an almost incompressible (quasi-fluid) behavior. As mentioned in Section 3, the significant development of excess pore water pressure in the lower parts of the core and very low rate of its dissipation are the main causes of forming this near-zero effective stress zone. This result is consistent with the observations (see Figure 4(a)).

During the impounding, the effect of buoyancy forces reduces the vertical effective stresses in the upstream shell. On the other hand, the core is almost under the undrained condition; therefore, the water pressure acting on the upstream side of the core increases the total stress. As a result, the size (or breadth) of regions with zero-effective stress and positioned next to (or near) the upstream side of the core decreases.

Figure 21 shows the contour distribution of shear strain in the main cross-section at the end of first impounding. In this figure, the oblique shear zones 


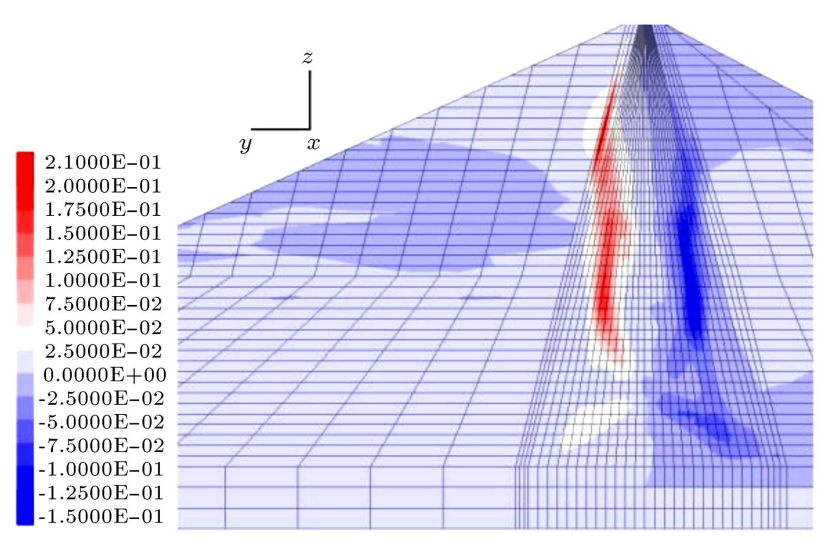

Figure 21. Contours of $z x$ shear strain at the end of the first impounding.

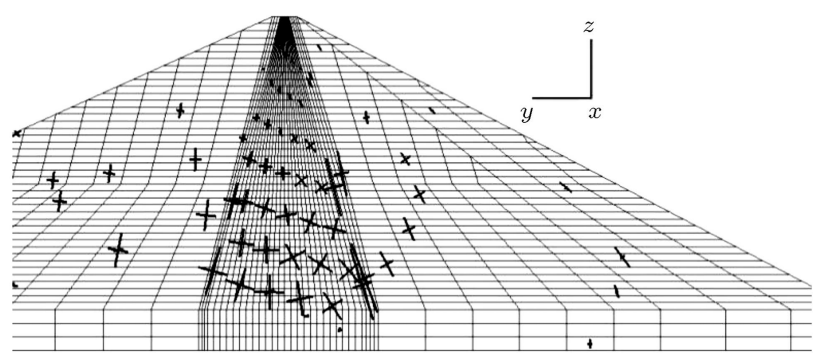

Figure 22. The direction of principal stresses $\sigma_{1}$ and $\sigma_{3}$ acting in the plane perpendicular to the dam axis at the end of the first impounding.

are clearly visible. As mentioned, because of high excess pore water pressure, the lower parts of the core exhibit an almost incompressible behavior. During the construction, the stage loading due to the placement of the upper parts of embankment is the main cause of creating these oblique shear zones. During the impounding, the combined effects of shear forces caused by the differential deformations of the upstream shell relative to the core and water pressure acting on the core lead to the further development of plastic shear deformations in the core. Increasing shear strains at the upstream core can provide stress conditions for forming hydraulic cracks. Moreover, in the core, such shear movement is associated with a volume decrease (contractive behavior) and is more likely to lead to a further rise rather than a relief of excess pore water pressures.

The direction of principal stresses $\sigma_{1}$ and $\sigma_{3}$ acting in the plane perpendicular to the dam axis in the main cross-section at the end of first impounding is shown in Figure 22. At lower levels of embankment, the identical magnitude of principal stresses in the central regions of the core and the rotation of directions of principal stresses in the vicinity of the filters are clearly evident. This result is consistent with the observations (see Figure 4(a)). As mentioned earlier, the rotation of directions of principal stresses is caused by the oblique shear zones (see Figure 4(b)).

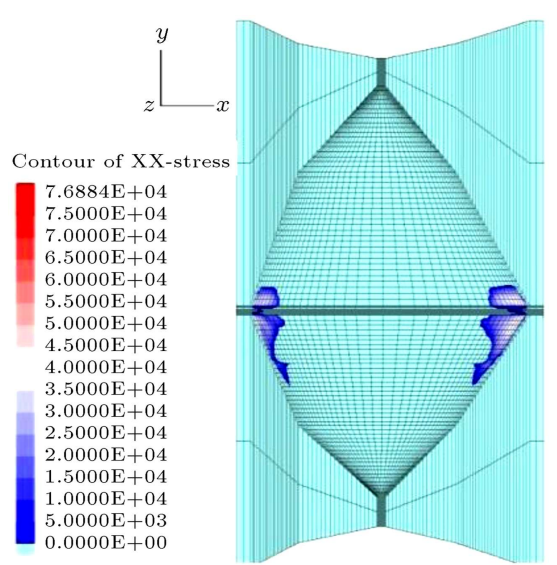

Figure 23. Contours of tensile stress $(\mathrm{Pa})$ along to dam axis at the end of the first impounding.

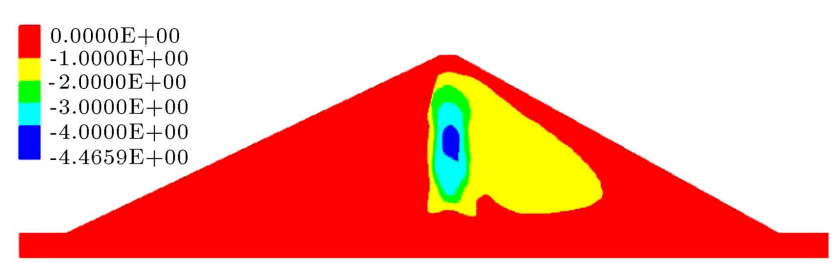

Figure 24. Contours of settlement $(\mathrm{m})$ at the end of construction.

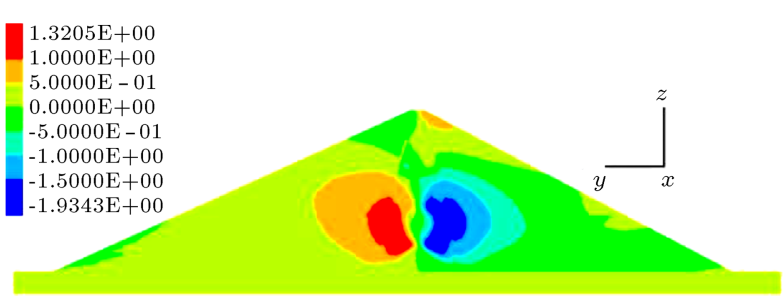

Figure 25. Contours of horizontal displacement (m) at the end of construction.

Figure 23 shows the contour distribution of tensile stress parallel to dam axis on the 3D model surface at the end of first impounding. This figure shows that those upper parts of the dam body that are positioned next to abutments have a tensile stress condition. These tensile regions have the greatest potential for developing transverse tensile cracks. The tensile region next to the right abutment is more extensive than the one next to the left abutment. These results correspond to the field observations. At the end of the first impounding, based on the results of this threedimensional model, the maximum depth of the tensile region in the dam body adjacent to the right and left abutments is almost 2 meters.

Figures 24 and 25 show the contour distribution of vertical and horizontal deformations in the main cross-section at the end of construction. Moreover, deformed mesh of the main cross-section at the end of construction is shown in Figure 26. As mentioned, during the construction, because of developing very 


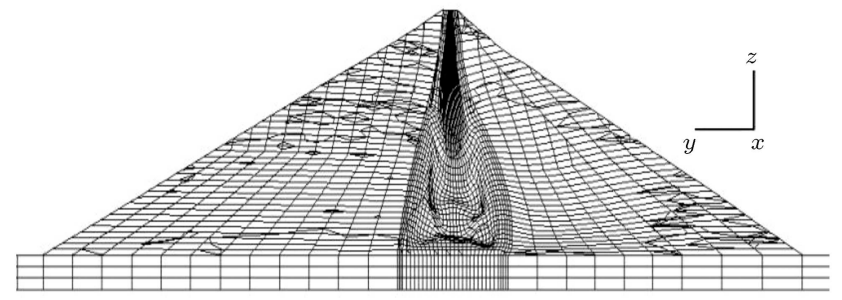

Figure 26. Deformed mesh of the main cross-section at the end of construction ( scale $=10: 1$ ).

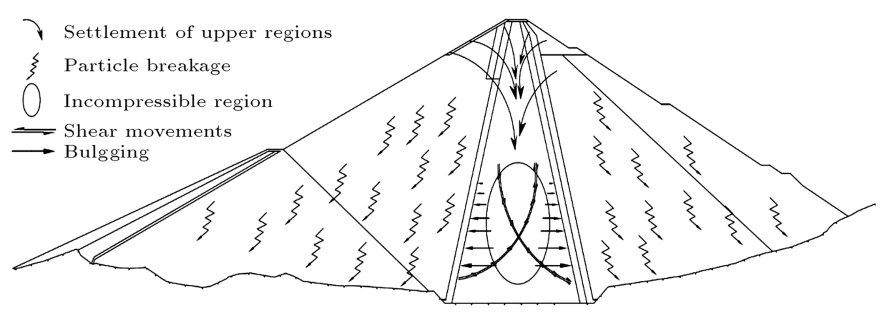

Figure 27. Schematic sketch of the deformation mechanism of the dam during the construction.

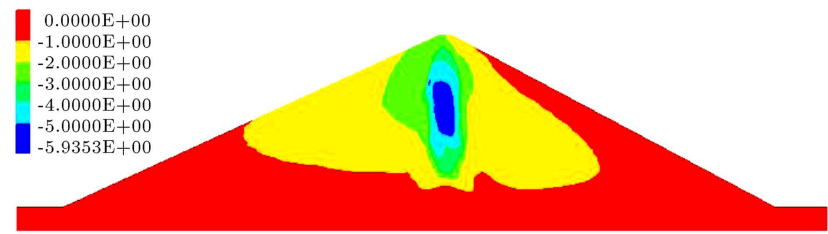

Figure 28. Contours of settlement $(\mathrm{m})$ at the end of the first impounding.

large excess pore pressure in the lower levels of the core and dissipating with a very low rate, the consolidation settlements were found insignificant. Settlements of the shells are mainly due to the effects of PSD, particle breakage, rotation, and rearrangement phenomena; however, those of the core are caused by internal oblique plastic shear movements. These oblique shear zones also lead to lateral deformations at the lower part of the core (bulging). The stage loading due to the placement of upper part of the dam puts the lower part of the core (which exhibits a quasi-fluid behavior) under vertical pressure. Over time, the lateral deformation of lower parts of the core causes the upper part of the dam to settle.

In the shells, region 3B has lower compressibility properties than other regions. Therefore, settlements of this zone are larger than those occurring in other zones. Schematically, Figure 27 shows a sketch of the deformation mechanism of this dam during the construction.

The contour distribution of settlement of the deformed mesh of the main cross-section and horizontal deformation in the main cross-section at the end of first impounding are shown in Figures 28 and 29. In addition, Figure 30 shows the contour distribution of settlement on the 3D model surface at the end

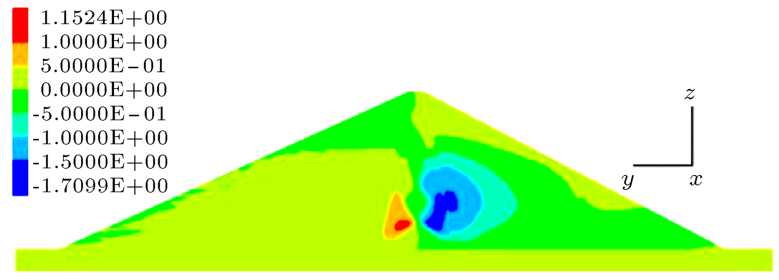

Figure 29. Contours of horizontal displacement $(\mathrm{m})$ at the end of the first impounding.

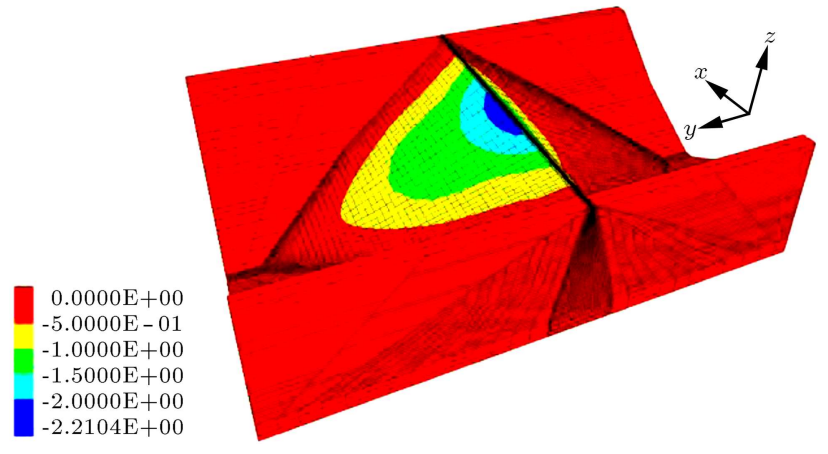

Figure 30. Contours of settlement $(\mathrm{m})$ on the dam surface at the end of the first impounding.

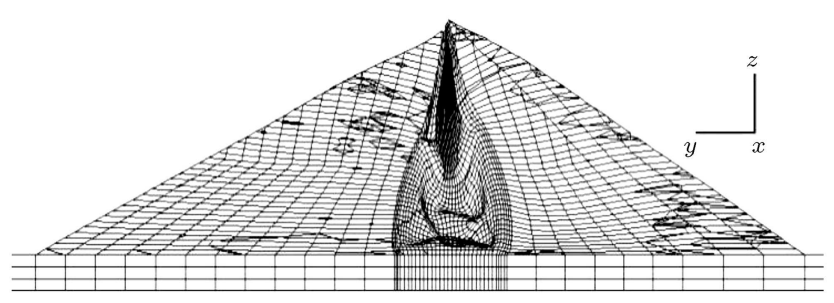

Figure 31. Deformed mesh of the main cross-section at the end of the first impounding ( scale $=10: 1$ ).

of the first impounding. The maximum settlements recorded inside the dam and on its crest are 5.93 and 2.2 meters, respectively. The upper parts of the upstream shell-core interface exhibit significant differential settlements. These differential settlements can cause longitudinal cracks in the crest during the operation. The lateral deformations in the lower parts of the core, especially on its upstream side, are smaller than those in the end of construction because of applying water pressure to the upstream face of the core. Figure 31 shows the deformed mesh of the main cross-section at the end of the first impounding. This figure shows berm-like subsidence in the upper parts of the upstream side of the body. This feature is consistent with the field observations. The collapse settlements of the upstream rockfill shell are the main cause of this deformation behavior during the first impounding. Figure 32 shows the schematic sketch of the deformation mechanism of the dam during the first impounding.

Now, 14 years after the first impounding, the excess pore pressure of the dam shows surprisingly 


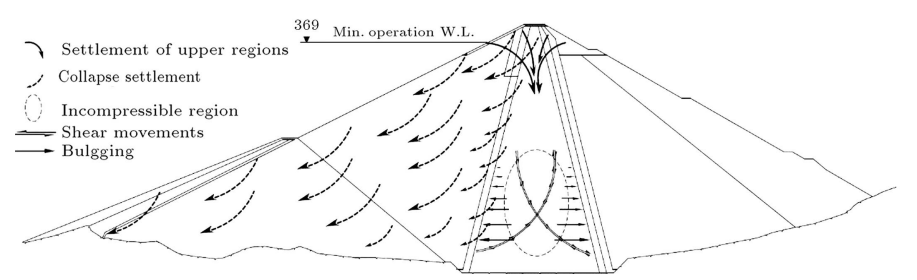

Figure 32. Schematic sketch of the deformation mechanism of the dam during the first impounding.

low dissipation (at most $10 \%$ in some piezometers); therefore, consolidation settlements of the core are still negligible; however, deformations of the dam surface are progressing with a significant rate. This progress occurs such that the crest now exhibits an approximately 5-meter settlement. Visibly deep transverse tensile cracks appeared on the crest situated next to the abutments, and an unusual berm-like longitudinal subsidence is observed on the upstream surface. Therefore, the long-term deformation mechanism of this dam can be the subject of further studies.

\section{Conclusions}

The results of this study can be summarized in two parts. In part one, this paper proposed a numerical method based on a well-known elasto-plastic hardening/softening constitutive model and Rowe's stressdilatancy theory to simulate the deformation behavior of coarse-grained materials, such as rockfills, due to Particle Size Distribution (PSD), particle breakage, rotation, and rearrangement under shearing. This method suggested a new mobilized dilation angle function that is a new version of Rowe's mobilized dilation angle function. This function has two factors: contraction factor, $I_{c}$, and reduction factor, $R_{c}$. These two parameters control the variation of plastic volumetric strain in the contraction and dilation phases under shearing, respectively. The results of the large-scale triaxial test conducted on the rockfill shell of the Masjed-e-Soleyman (MES) Dam showed that this material had a high potential of particle breakage, which leads to high amount of volumetric plastic strains. The numerical simulation of these triaxial tests indicated that the constitutive model, modified with new dilation mobilized dilation angle function, could estimate the deformation behavior of the MES rockfill materials accurately.

In part two, to achieve the main objective of this study, first, the data recorded by the instruments installed inside the dam body were carefully studied and, then, a three-dimensional numerical model of the dam was developed to simulate its deformation behavior. The calculations were carried out via simultaneous use of flow and mechanical formulations. The mechanical behavior of embankment materials was idealized by the modified hardening/softening constitutive model. The main results of this part of research are as follows:

1. A number of factors such as lower parts of the core that have been compacted wet of optimum, the very low permeability of the core, and the relatively high rate of construction led to the significant development of excess pore water pressure in the core during the construction. Considerable pore pressure of the core led to the formation of a region with near-zero effective stress in the lower parts of the core. This region has an isotropic stress condition so that part of the core within this region is expected to exhibit an incompressible or quasi-fluid behavior. In addition, the reducing permeability of the core with the further dissipation of excess pore pressure next to the filters led to a slowing rate (speed) of dissipation of excess pore pressure. The insignificant dissipation of excess pore pressure in the core led to unexpectedly small consolidation settlements during the construction;

2. The stage loading due to the placement of the upper layers of the dam led to the formation of oblique plastic shear zones inside the lower parts of the core. These plastic shear movements led to the settlement of the upper part of the embankment and lateral deformation (bulging) of the lower part of the core. The increased pore pressure of the core can be another outcome of these plastic shear deformations. Fairly significant deformations observed in the shell are mainly due to the effects of PSD, rearrangement, rotation, and especially particle breakage phenomena on the deformation of the shells, drainages, and filters. To simulate the volumetric deformations caused by these phenomena, in part one, authors modified Row's mobilized dilation function and incorporated it into the hardening/softening constitutive model;

3. During the first impounding, water presser acting on the core and most likely the oblique plastic shear movements inside the core increased its excess pore pressure. On the other hand, the water presser acting on the core (E1) increased its effective stress on the upstream side of the core and, therefore, reduced the extension of the zero-stress region, making it smaller than what it was at the end of construction;

4. During the first impounding, collapse settlements of the upstream rockfill shell were the most important factors in the deformation behavior of the dam during the first impounding. This study utilized a concept known as "stress reduction factor" to simulate the collapse settlement phenomenon. The collapse settlements of the upstream rockfill shell caused significant differential settlements at the 
upper levels of the upstream filter-core interface and, also, led to the further development of plastic shear deformations inside the core;

5. At the end of the first impounding, those upper parts of the dam body that are positioned next to abutments have a tensile stress condition. These tensile regions have the greatest potential for developing transverse tensile cracks. The tensile region next to the right abutment is more extensive than one next to the left abutment. Based on the results of this three-dimensional model, the maximum depth of the tensile region in the dam body adjacent to the right and left abutments is almost 2 meters.

\section{Acknowledgment}

The work described in this paper was supported by Ferdowsi University of Mashhad (Grant No. 39112.2) and could not have been performed without assistance of Abpooy Coinsulting Group's staffs that provided for us required laboratory and field data. The largescale triaxial tests were performed at Institute of Soil and Rock Mechanics of Karlsruhe University, which was commissioned by Iran Water and Power Resources Development Company (I.W.P.C) Ministry of Energy Iran. Special thanks are given to Mr. Arab from Khuzestan Water and Power Authority for his assistance.

\section{Nomenclature}

$f^{s}, f^{t} \quad$ Shear and tensile yield functions

$\sigma_{1}, \sigma_{3} \quad$ Maximum and minimum principal stresses

$\sigma_{y}^{\prime} \quad$ Vertical effective stress

$\varphi_{m} \quad$ Mobilized friction angle

$\varphi_{0} \quad$ Initial mobilized friction angle

$\varphi_{p} \quad$ Peak friction angle

$\varphi_{c v} \quad$ Critical state friction angle

$\varphi_{s} \quad$ Angle of internal friction at $\sigma_{3}=100$ $\mathrm{kPa}$

$\Delta \varphi \quad$ Reduction in friction angle in respect to confining pressure for each 10 fold increase in $\sigma_{3}$

$Q^{S}, Q^{t} \quad$ Shear and tensile plastic potential functions

$\psi_{m} \quad$ Mobilized dilation angle

$\psi_{p} \quad$ Peak dilation angle

$\psi_{m R} \quad$ Mobilized dilation angle obtained from the Rowe's equation

C Cohesion

$C_{m} \quad$ Mobilized cohesion

$\begin{array}{ll}\sigma_{m}^{t} & \text { Mobilized tensile strength } \\ \varepsilon_{v}^{p} & \text { Plastic volumetric strain } \\ \varepsilon_{s}^{p} & \text { Plastic shear strain } \\ \varepsilon_{f}^{s} & \text { Plastic shear strain at peak friction } \\ & \text { angle } \\ \varepsilon_{1} & \text { Axial strain } \\ \varepsilon_{v} & \text { Volumetric strain } \\ R_{d} & \text { Reduction factor } \\ I_{c} & \text { Contraction factor } \\ E & \text { Young's modulus } \\ n & \text { Exponent of elastic modulus and } \\ & \text { porosity } \\ K & \text { Elastic modulus and permeability } \\ v & \text { tensor } \\ P_{a} & \text { Poisson } \\ K_{i n t} & \text { Atmospheric pressure } \\ k_{r} & \text { Intrinsic permeability } \\ S_{w} & \text { Relative permeability } \\ q & \text { Saturation degree } \\ d & \text { Deviator stress } \\ \rho_{d} & \text { Dilation } \\ & \text { Dry density }\end{array}$

\section{References}

1. Cetin, H., Laman, M., and Ertunç, A. "Settlement and slaking problems in the world's fourth largest rockfill dam, the Ataturk Dam in Turkey", Engineering Geology, 56, pp. 225-242 (2000).

2. Xing, H.F., Gong, X.N., Zhou, X.G., and Fu, H.F. "Construction of concrete-faced rockfill dams with weak rocks", J. Geotech. Geoenviron. Eng., 132(6), pp. 778-785 (2006).

3. Costa, L.M. and Alonso, E.E. "Predicting the behavior of an earth and rockfill dam under construction", Journal of Geotechnical and Geoenvironmental Engineering, ASCE, 135(7), pp. 851-862 (2009).

4. Akhtarpour, A. and Khodaii, A. "A study of the seismic response of asphaltic concrete used as a core in rockfill dams", Journal of Seismology and Earthquake Engineering, 16, pp. 169-184 (2014).

5. Wang, Z., Liu, S., Vallejo, L., and Wang, L. "Numerical analysis of the causes of face slab cracks in Gongboxia rockfill dam", Engineering Geology, 181, pp. 224-232 (2014).

6. Kim, Y.S., Seo, M.W., Lee, C.W., and Kang, G.C. "Deformation characteristics during construction and after impoundment of the CFRD-type Daegok Dam, Korea", Engineering Geology, 178, pp. 1-14 (2014).

7. Mahinroosta, R., Aliadeh, A., and Gatmiri, B. "Simulation of collapse settlement of first filling in a high rockfill dam", Engineering Geology, 187, pp. 32-44 (2015). 
8. Marsal, R.J. "Large scale testing of rock fill materials", J. Soil Mech. Found. Div. ASCE, 93(2), pp. 27-43 (1967).

9. Marschi, N.D., Chan, C.K., and Seed, H.B. "Evaluation of properties of rockfill materials", J. Soil Mech. Found. Div., ASCE, 98(1), pp. 95-114 (1972).

10. Indraratna, B., Wijewardena, L.S.S., and Balasubramaniam, A.S. "Large-scale triaxial testing of greywacke rockfill", Geotechnique, 43(1), pp. 37-51 (1993).

11. Varadarajan, A., Sharma, K.G., Venkatachalam, K., and Gupta, A.K. "Testing and modeling two rockfill materials", J. Geotech. Geoenviron. Eng., 129(3), pp. 206-206 (2003).

12. Vasistha, Y., Gupta, A.K., and Kanwar, V. "Medium triaxial testing of some rockfill materials", Electron. J. Geotech. Eng., 18(Bund. D), pp. 923-964 (2013).

13. Xiao, Y., Liu, H., Chen, Y., and Jiang, J. "Strength and deformation of rockfill material based on largescale triaxial compression tests. I: influences of density and pressure", Journal of Geotechnical and Geoenvironmental Engineering, 140(12), Article ID 04014070 (2014).

14. Xiao, Y., Liu, H., Chen, Y., and Jiang, J. "Strength and deformation of rockfill material based on largescale triaxial compression tests. II: influence of particle breakage", Journal of Geotechnical and Geoenvironmental Engineering, 140(12), Article ID 04014071 (2014).

15. Khoiri, M., Ou, C.Y., and Teng, F.C. "A comprehensive evaluation of strength and modulus parameters of a gravelly cobble deposit for deep excavation analysis", Engineering Geology, 174, pp. 61-72 (2014).

16. Duncan, J.M. and Chang, C.Y. "Nonlinear analysis of stress and strain in soils", J. Soil Mech. Found. Div., ASCE, 96(5), pp. 1629-53 (1970).

17. Lade, P.V. and Kim, M.K. "Single hardening constitutive model for soil, rock and concrete", Inter. J. Solids and Structures, 32(14), pp. 1963-1978 (1995).

18. Nova, R. and Wood, D.M. "A constitutive model for sand in triaxial compression", Inter. J. for Numerical and Analytical Methods in Geomechanics, 3(3), pp. 255-278 (1979).

19. Lade, P.V. and Duncan, J.M. "Elastoplastic stressstrain theory for cohesionless soil", J. Geotech. Engin. Div., ASCE, 101(GT10), pp. 1037-1053 (1975).

20. Guo, R. and Li, G. "Elasto-plastic constitutive model for geotechnical materials with strain-softening behavior", Comput. Geotech., 34, pp. 14-23 (2008).

21. Kulhawy, F.H. and Duncan, J.M. "Stresses and movements in Oroville dam", J. Soil Mech. Found. Div., ASCE, 98(7), pp. 653-665 (1972).

22. Escuder, I., Andreu, J., and Reche, M. "An analysis of stress-strain behaviour and wetting effects on quarried rock shells", Can. Geotech. J., 42(1), pp. 51-60 (2005).
23. Varadarajan, A., Sharma, K.G., Abbas, S.M., and Dhawan, A.K. "Constitutive model for rockfill materials and determination", Int. J. Geomech., 6(4), pp. 226-237 (2006).

24. Veiskarami, M., Ghorbani, A., and Alavipour, M.R. "Development of a constitutive model for rockfills and similar granular materials based on the disturbed state concept", Front. Struct. Civ. Eng., 6(4), pp. 365-378 (2012).

25. Xu, M. and Song, E. "Numerical simulation of the shear behavior of rockfills", Comput. Geotech., 36(8), pp. 1259-1264 (2009).

26. Xiao, Y., Liu, H., Chen, Y., and Jiang, J. "Testing and modeling of the state-dependent behaviors of rockfill material", Comput. Geotech., 6(1), pp. 153165 (2014c).

27. Feda, J. "Note on the effect of grain-crashing on the granular soil behavior", Engineering Geology, 63, pp. 93-98 (2002).

28. Miura, S., Yagi, K., and Asonuma, T. "Deformationstrength evaluation of crushable volcanic soils by laboratory and in-situ testing", Soils Found., 43(4), pp. 47-57 (2003).

29. Einav, I. "Breakage mechanics-Part I: Theory", J. Mech. Phys. Solids, 55(6), pp. 1274-1297 (2007a).

30. Einav, I. "Soil mechanics: Breaking ground", Philos. Trans. R. Soc. London, Ser. A, 365(1861), pp. 29853002 (2007).

31. Bandini, V. and Coop, M.R. "The influence of particle breakage on the location of the critical state line of sands", Soils Found., 51(4), pp. 591-600 (2011).

32. Salim, W. and Indraratna, B. "A new elastoplastic constitutive model for coarse granular aggregates incorporating particle breakage", Can. Geotech. J., 41(4), pp. 657-671(2004).

33. Barden, L., McGown, A., and Collins, K. "The collapse mechanism in partly saturated soil", Engineering Geology, 7(1), pp. 49-60 (1973)

34. Marsal, R.J., Mechanical Properties of Rock Fill, In: R.C. Hirshfeld and S.J. Poulos, Eds., EmbankmentDam Engineering, Casagrande Volume, John Wiley \& Sons Inc., N.Y., pp. 109-200 (1973).

35. Maswoswe, J. "Stress paths for a compacted soil during collapse due to wetting", PhD Thesis, Imperial College, University of London (1985).

36. Egretli, I. and Singh, R.N. "A laboratory investigation into the effects of air void and water saturation on the collapse settlement of opencast mine backfill", Min. Sci. Technol., 7, pp. 87-97 (1988).

37. Nouaouria, M.S., Guenfoud, M., and Lafifi, B. "Engineering properties of loess in Algeria", Engineering Geology, 99(2), pp. 85-89 (2008).

38. Mahinroosta, R. and Oshtaghi, V. "Effect of saturation on the shear strength and collapse settlement of gravelly material using direct shear test apparatus", Sharif J. Sci. Technol., 29(1), pp. 103-114 (2013). 
39. Squier, L.R. "Load transfer in earth and rockfill dams", J. Soil Mech. Found. Div., ASCE, 96(SM1), pp. 213233 (1970).

40. Hunter, G.J. "The pre- and post-failure deformation behaviour of soil slopes", PhD Thesis, University of New South Wales, Australia (2003).

41. Nobari, E.S. and Duncan, J.M. "Effect of reservoir filling on stresses and movements in earth and rockfill dams", Report TE-72-1, University of California, Department of Civil Engineering (1972).

42. Naylor, D.J., Maranha das Neves, E., Mattar, J.D., and Veiga Pinto, A.A. "Prediction of construction performance of Beliche Dam", Geotechnique, 36(3), pp. 359-376 (1986).

43. Naylor, D.J., Maranha, J.R., Maranha das Neves, E., and Veiga Pinto, A.A. "A back-analysis of Beliche Dam", Geotechnique, 47(2), pp. 221-233 (1997).

44. Maranha das Neves, E. and Veiga Pinto, A. "Modeling collapse on rockfill dams", Comput. Geotech, 6, pp. 131-153 (1988).

45. Alonso, E.E., Olivella, S., and Pinyol, N.M. "A review of Beliche Dam", Geotechnique, 55(4), pp. 267-285 (2005).

46. Lloret, A. and Alonso, E.E. "Consolidation of unsaturated soils including swelling and collapse behavior", Geotechnique, 30(4), pp. 449-477 (1980).

47. Oldecop, L.A. and Alonso, E.E. "A model for rockfill compressibility", Geotechnique, 51(2), pp. 127-139 (2001).

48. Oldecop, L.A. and Alonso, E.E. "Suction effects on rockfill compressibility", Geotechnique, 53(2), pp. 289292 (2003).

49. Mahinroosta, R. and Alizadeh, A. "Simulation of collapse settlement in rockfill material due to saturation", Inter. J. Civ. Engin., 10(2), pp. 102-108 (2012).

50. Itasca Consulting Group, Inc. FLAC3D, User's Manuals, Minneapolis, Minnesota (2012).

51. Moshanir Power Engineering Consultants, Review on Additional Laboratory Tests on Materials of Masjed-eSoleyman Dam, Tehran, Iran (1996).

52. Araei, A.A., Soroush, A., and Rayhani, M. "Largescale triaxial testingand numerical modeling of rounded and angular rockfill materials", Scientia Iranica, 17(3), pp. 169-183 (2010).

53. Soroush, A. and Jannatiaghdam, R. "Behavior of rockfill materials in triaxial compression testing", Inter. J. Civ. Engin, 10(2), pp. 153-161 (2012).

54. Vermeer, P.A. and De Borst, R. "Non-associated plasticity for soils, concrete and rock", Heron., 29(3), pp. 1-64 (1984).

55. Rowe, P.W. "Stress-dilatancy, earth pressure and slopes", J. Soil Mech. Found. Div., ASCE, 89(5), pp. 37-61(1963).

56. Karlsruhe University, Masjed-e-Soleyman Dam HPP: Investigations on Coarse-grain Materials, Institute of Soil and Rock Mechanics, Karlsruhe University, Germany (1996).
57. Ramamurthy, T. and Gupta, K.K. "Response paper to how ought one to determine soil parameters to be used in the design of earth and rockfill dams", In Proceedings of Indian Geotechnical Conference, New Delhi, India, 2, pp. 15-19 (1986).

58. Naderian, A.R. and Williams, D.J. "Bearing capacity of open coal-mine backfill materials", Trans. Inst. Min. Metal, 106, pp. A30-A34 (1997).

59. Nahazanan, H., Clarke, S., Asadi, A., Yusoff, Z.M., and Huat, B.K. "Effect of inundation on shear strength characteristics of mudstone backfill", Engineering Geology, 158, pp. 48-56 (2013).

60. Hasanzadehshooiili, H., Mahinroosta, R., Lakirouhani, A., and Oshtaghi, V. "Using artificial neural network (ANN) in prediction of collapse settlements of sandy gravels", Arab. J. Geosci., 7(6), pp. 2303-2314 (2014).

61. Pagano, L., Sica, S., and Desideri, A. "Representativeness of measurements in the interpretation of earth dam behavior", Canadian Geotechnical Journal, 43(1), pp. 87-99 (2006).

\section{Appendix}

\section{Formulation of Fluid Analysis in FLAC soft- ware}

The flow formulation implemented in the FLAC3D software [50] is presented as follows.

Water transport is assumed to be governed by Darcy's law:

$$
q=-K \cdot \nabla\left(u_{w}-\gamma_{w} Z\right),
$$

where $q$ is the vector of water flow, $u_{w}$ is the pore water pressure, and $K$ is the permeability.

Mass conservation equation of water phase can be written as follows:

$$
\frac{\partial \xi}{\partial t}+\operatorname{div} q=q_{v}
$$

where $\xi$ is the variation of fluid content (variation of fluid volume per unit volume of porous material), and $q_{v}$ is a scalar quantity related to the volumetric fluid source intensity.

Following the formulation of deformationdiffusion processes based on quasi-static Biot theory, Eq. (A.3) is implemented in FLAC3D:

$$
\frac{\partial u_{w}}{\partial t}=M\left(\frac{\partial \xi}{\partial t}-\alpha \frac{\partial \varepsilon_{v}}{\partial t}\right)
$$

where $\varepsilon_{v}$ is the volumetric strain, and $M, \alpha$ are the Biot modulus and the Biot coefficient, respectively. Ignoring the compressibility of solid matrix (that is, grains) compared to that of the deformable skeleton, we have:

$$
M=\frac{K_{W}}{n}, \quad \alpha=1,
$$

where $K_{w}$ is the fluid bulk modulus. 


\section{Biographies}

Ali Akhtarpour graduated from Polytechnic University of Tehran and received BSc degree in Civil Engineering, MSc degree (under supervision of Dr. Abbas Soroush), and $\mathrm{PhD}$ degree (under supervision of Dr. Ali Khodaii) in Geotechnical Engineering in 2000, 2003, and 2011, respectively. Now, he is an Assistant Professor in Engineering Faculty at Ferdowsi University of Mashhad, Mashhad, Iran. In addition, he has some experience in the embankment dam design, monitoring, and numerical modeling for more than 18 years. He is the technical head of a consulting engineering company in Mashhad, Iran.

Morteza Salari received an MSc degree in Geotechnical Engineering from Ferdowsi University of Mashhad, Mashhad, Iran, in 2009. He is now an Expert in Abpooy Consulting Engineering Company in Mashhad. Further, he has some experience in the field of embankment dam engineering for 8 years. He is a PhD student at Ferdowsi University of Mashhad, Mashhad, Iran. 